\title{
Effects of thermodynamics, dynamics and aerosols on cirrus clouds based on in situ observations and NCAR CAM6
}

\author{
Ryan Patnaude ${ }^{1}$, Minghui Diao ${ }^{1}$, Xiaohong $\mathrm{Liu}^{2}$, and Suqian $\mathrm{Chu}^{3}$ \\ ${ }^{1}$ Department of Meteorology and Climate Science, San Jose State University, San Jose, CA 95192, USA \\ ${ }^{2}$ Department of Atmospheric Sciences, Texas A\&M University, College Station, TX 77843, USA \\ ${ }^{3}$ Department of Atmospheric Science, University of Wyoming, Laramie, WY 82071, USA
}

Correspondence: Minghui Diao (minghui.diao@sjsu.edu)

Received: 24 May 2020 - Discussion started: 3 July 2020

Revised: 11 December 2020 - Accepted: 16 December 2020 - Published: 10 February 2021

\begin{abstract}
Cirrus cloud radiative effects are largely affected by ice microphysical properties, including ice water content (IWC), ice crystal number concentration $\left(N_{\mathrm{i}}\right)$ and mean diameter $\left(D_{\mathrm{i}}\right)$. These characteristics vary significantly due to thermodynamic, dynamical and aerosol conditions. In this work, a global-scale observation dataset is used to examine regional variations of cirrus cloud microphysical properties, as well as several key controlling factors, i.e., temperature, relative humidity with respect to ice (RHi), vertical velocity $(w)$ and aerosol number concentrations $\left(N_{\mathrm{a}}\right)$. Results are compared with simulations from the National Center for Atmospheric Research (NCAR) Community Atmosphere Model version 6 (CAM6). Observed and simulated ice mass and number concentrations are constrained to $\geq 62.5 \mu \mathrm{m}$ to reduce potential uncertainty from shattered ice in data collection. The differences between simulations and observations are found to vary with latitude and temperature. Comparing with averaged observations at $\sim 100 \mathrm{~km}$ horizontal scale, simulations are found to underestimate (overestimate) IWC by a factor of 3-10 in the Northern (Southern) Hemisphere. Simulated $N_{\mathrm{i}}$ is overestimated in most regions except the Northern Hemisphere midlatitudes. Simulated $D_{\mathrm{i}}$ is underestimated by a factor of 2 , especially for warmer conditions $\left(-50\right.$ to $\left.-40^{\circ} \mathrm{C}\right)$, possibly due to misrepresentation of ice particle growth/sedimentation. For RHi effects, the frequency and magnitude of ice supersaturation are underestimated in simulations for clear-sky conditions. The simulated IWC and $N_{\mathrm{i}}$ show bimodal distributions with maximum values at $100 \%$ and $80 \% \mathrm{RHi}$, differing from the unimodal distributions that peak at $100 \%$ in the observations. For $w$ effects, both observations and simulations show variances of $w$
\end{abstract}

$\left(\sigma_{w}\right)$ decreasing from the tropics to polar regions, but simulations show much higher $\sigma_{w}$ for the in-cloud condition than the clear-sky condition. Compared with observations, simulations show weaker aerosol indirect effects with a smaller increase of IWC and $D_{\mathrm{i}}$ at higher $N_{\mathrm{a}}$. These findings provide an observation-based guideline for improving simulated ice microphysical properties and their relationships with key controlling factors at various geographical locations.

\section{Introduction}

Cirrus clouds represent one of the most ubiquitous cloud types with an estimated global coverage of approximately $20 \%$ to $40 \%$ (Mace and Wrenn, 2013; Sassen et al., 2008). According to the fifth assessment report of the United Nations Intergovernmental Panel on Climate Change (IPCC) (Boucher et al., 2013), the largest uncertainty in estimating future climate change stems from clouds and aerosols. Unlike most other cloud types, cirrus clouds may produce a net positive or negative radiative forcing depending on their microphysical properties (Stephens and Webster, 1981; Zhang et al., 1999), which are affected by meteorological conditions and aerosol distributions. Tan et al. (2016) showed that the radiative effects of misrepresenting the prerequisite condition of cirrus clouds - ice supersaturation (ISS, where relative humidity with respect to ice (RHi) $>100 \%$ ) - can lead to an average bias of $+2.49 \mathrm{~W} \mathrm{~m}^{-2}$ at the top of the atmosphere. Other modeling studies found large differences in the net cloud radiative forcing depending on the fraction of activated ice-nucleating particles (INPs) and the nucle- 
ation mechanisms (i.e., homogeneous and heterogeneous nucleation) through which the clouds form (Liu et al., 2012; Storelvmo and Herger, 2014). The large uncertainties in cirrus cloud radiative forcing illustrate the need for further study of cirrus cloud microphysical properties as well as their controlling factors in various geographical locations.

Ideally, a comprehensive quantification of cirrus cloud microphysical properties globally based on high-resolution, in situ observations would mitigate many uncertainties. However, challenges remain in field measurements to achieve such spatial coverage. Previously, efforts have been made to understand cirrus cloud properties based on their geographical locations. Diao et al. (2014b) performed a hemispheric comparison of in situ cirrus evolution and found little difference in the clear-sky ISS frequency as well as the proportion of each evolution phase between the Northern Hemisphere and Southern Hemisphere (NH and $\mathrm{SH}$, respectively). In situ observations of tropical, midlatitude and polar cirrus clouds have shown that ice water content (IWC) can vary orders of magnitude depending on the geographical locations (Heymsfield, 1977; Heymsfield et al., 2005, 2017; Mcfarquhar and Heymsfield, 1997; Schiller et al., 2008). Wolf et al. (2018) used balloon-based in situ observations to analyze microphysical properties of Arctic ice clouds and found differences in particle size distributions (PSDs) depending on the cloud origin. Krämer et al. $(2016,2020)$ developed a cirrus cloud climatology, focusing on tropical and midlatitude cirrus clouds, and showed that cloud thickness is larger at lower altitudes and thus produces a more negative radiative forcing. Moving from north to south using lidar-based observations from two research cruises starting from Leipzig, Germany, one to Punta Arenas, Chile, and the other one to Stellenbosch, South Africa, Kanitz et al. (2011) observed a decrease in the efficiency of heterogeneous nucleation in the $\mathrm{SH}$, which could be a result of fewer INPs. This hemispheric difference in aerosol indirect effects is consistent with significantly higher aerosol number concentrations in the $\mathrm{NH}$ (Minikin et al., 2003). Using satellite observations from the Cloud-Aerosol Lidar and Infrared Pathfinder Satellite Observation (CALIPSO), Mitchell et al. (2018) showed the dependence of ice particle effective diameter on temperature, latitude, season and topography. Thorsen et al. (2013) used CALIPSO data to examine cloud fraction of tropical cirrus clouds and showed dependence on altitude and diurnal cycle. Tseng and Fu (2017) used CALIPSO and Constellation Observing System for Meteorology, Ionosphere, and Climate (COSMIC) data and found that the tropical coldpoint tropopause temperature is a controlling factor of cirrus cloud fraction in the tropical tropopause layer.

Regional and hemispheric variations of cirrus microphysical properties are produced by various controlling factors, such as thermodynamics (i.e., temperature and RHi), dynamics (e.g., vertical velocity) and aerosols (e.g., number concentration and composition). The effects of temperature have been extensively studied from in situ observations (Heyms- field et al., 2017; Luebke et al., 2013, 2016; Schiller et al., 2008), showing an increase of IWC towards warmer temperatures. A number of studies focused on distributions of RHi have found that in-cloud RHi occurs most frequently at or near $100 \%$ (Jensen et al., 2001; Krämer et al., 2009). Another study by Diao et al. (2017) found that using different RHi thresholds (e.g., $108 \%$ to $130 \%$ ) for ice nucleation in simulations can influence IWC and ice crystal number concentrations $\left(N_{\mathrm{i}}\right)$ in convective cirrus. In addition, the spatial scales of ice-supersaturated regions can vary from the microto mesoscales, largely depending on the spatial variability of water vapor (Diao et al., 2014a). The distributions of vertical velocity have been investigated in different types of cirrus clouds, such as in ridge-crest cirrus, frontal cirrus and anvil cirrus (Muhlbauer et al., 2014a, b). Stronger updrafts are found to be associated with higher occurrence frequency of ISS inside anvil and convective cirrus (D'Alessandro et al., 2017). Regarding the effects of aerosols, Cziczo et al. (2013) and Cziczo and Froyd (2014) investigated ice crystal residuals from in situ observations and discovered that the majority of midlatitude cirrus clouds form via heterogeneous nucleation on mineral dust and metallic particles. Anthropogenic aerosols, such as secondary organic aerosols, were found to be less effective INPs compared with mineral dust (Prenni et al., 2009). Based on remote sensing data, Zhao et al. (2018, 2019) showed that the correlations between ice crystal sizes and aerosol optical depth can be either positive or negative depending on the meteorological conditions in convective clouds. Chylek et al. (2006) showed an increase in ice crystal size during the more polluted winter months compared with cleaner summer months over the eastern Indian Ocean, which the authors speculate to be due to heterogeneous nucleation occurring at lower ice supersaturation compared with homogeneous nucleation, therefore reducing the ambient ice supersaturation magnitude and making homogeneous nucleation a more difficult pathway. Using a global-scale dataset of multiple flight campaigns, Patnaude and Diao (2020) isolated individual effects on cirrus clouds from temperature, RHi, vertical velocity $(w)$ and aerosol number concentrations $\left(N_{\mathrm{a}}\right)$. They found that when $N_{\mathrm{a}}$ is 3-10 times higher than average conditions, it shows strong positive correlations with cirrus microphysical properties such as IWC, $N_{\mathrm{i}}$ and numberweighted mean diameter $\left(D_{\mathrm{i}}\right)$. These aerosol indirect effects are also susceptible to whether or not thermodynamic and dynamical conditions are controlled, demonstrating the importance of conducting a comprehensive analysis of various key controlling factors altogether.

More recently, in situ observations have been used to evaluate and improve cirrus cloud parameterizations in global climate models (GCMs). Two types of simulations have been frequently used for model evaluation, i.e., free-running (Eidhammer et al., 2014, 2017; Wang and Penner, 2010; Zhang et al., 2013) and nudged (D'Alessandro et al., 2019; Kooperman et al., 2012; Wu et al., 2017) simulations. For freerunning simulations, a comparison on statistical distributions 
of ice microphysical properties is often used for model validation (e.g., Penner et al., 2009). The nudged simulation would nudge certain meteorological conditions towards reanalysis data, such as horizontal wind and temperature (e.g., D'Alessandro et al., 2019; Wu et al., 2017). These nudged simulations can also be output to a similar location and time to those of the aircraft observations. Given the importance and limited understanding of how aerosols interact with cirrus clouds, much attention has been dedicated to the parameterization of aerosol indirect effects (Kärcher and Lohmann, 2002, 2003; Kuebbeler et al., 2014; Wang et al., 2014a). Shi et al. (2015) added the effects of pre-existing ice into the Community Atmosphere Model version 5 (CAM5) and found a decrease in $N_{\mathrm{i}}$ with increasing aerosol concentration due to the reduction of homogeneous nucleation frequency. Other studies also investigated the effect of updraft velocity on simulated $N_{\mathrm{i}}$ and aerosol indirect effects (Zhou et al., 2016; Penner et al., 2018).

This study aims to bridge the knowledge gap on how cirrus clouds vary depending on geographical locations and environmental conditions by using a comprehensive in situ observation dataset that includes seven US National Science Foundation (NSF) flight campaigns. Observations were collected aboard the NSF/National Center for Atmospheric Research (NCAR) Gulfstream V (GV) research aircraft. Descriptions of the seven flight campaigns, instrumentations, model configurations of the NCAR Community Atmosphere Model version 6 (CAM6) are provided in Sect. 2. Both observations and simulations are used to examine the regional variations in the statistical distributions of cirrus microphysical properties, including IWC, $N_{\mathrm{i}}$ and $D_{\mathrm{i}}$ (Sect. 3). Impacts of several key controlling factors, i.e., temperature, RHi, $w$ and $N_{\mathrm{a}}$, are examined in Sect. 4. Discussions on observationbased findings and model evaluation results are included in Sect. 5.

\section{Data and methods}

\subsection{In situ observations and instrumentations}

In this study, in situ airborne observations at $1 \mathrm{~Hz}$ are provided by instruments aboard the NSF High-Performance Instrumented Airborne Platform for Environmental Research (HIAPER) GV research aircraft. A comprehensive global dataset is compiled based on seven major flight campaigns funded by the NSF, including START08 (Pan et al., 2010), HIPPO deployments 2-5 (Wofsy, 2011), PREDICT (Montgomery et al., 2012), TORERO (Volkamer et al., 2015), DC3 (Barth et al., 2015), CONTRAST (Pan et al., 2017) and ORCAS (Stephens et al., 2018). Table 1 provides a detailed summary of the seven flight campaigns, including location, duration of flights, total flight hours of all temperatures and flight hours for in-cloud and clear-sky conditions at temperatures $\leq-40^{\circ} \mathrm{C}$ only. Maps comparing the flight tracks of in situ
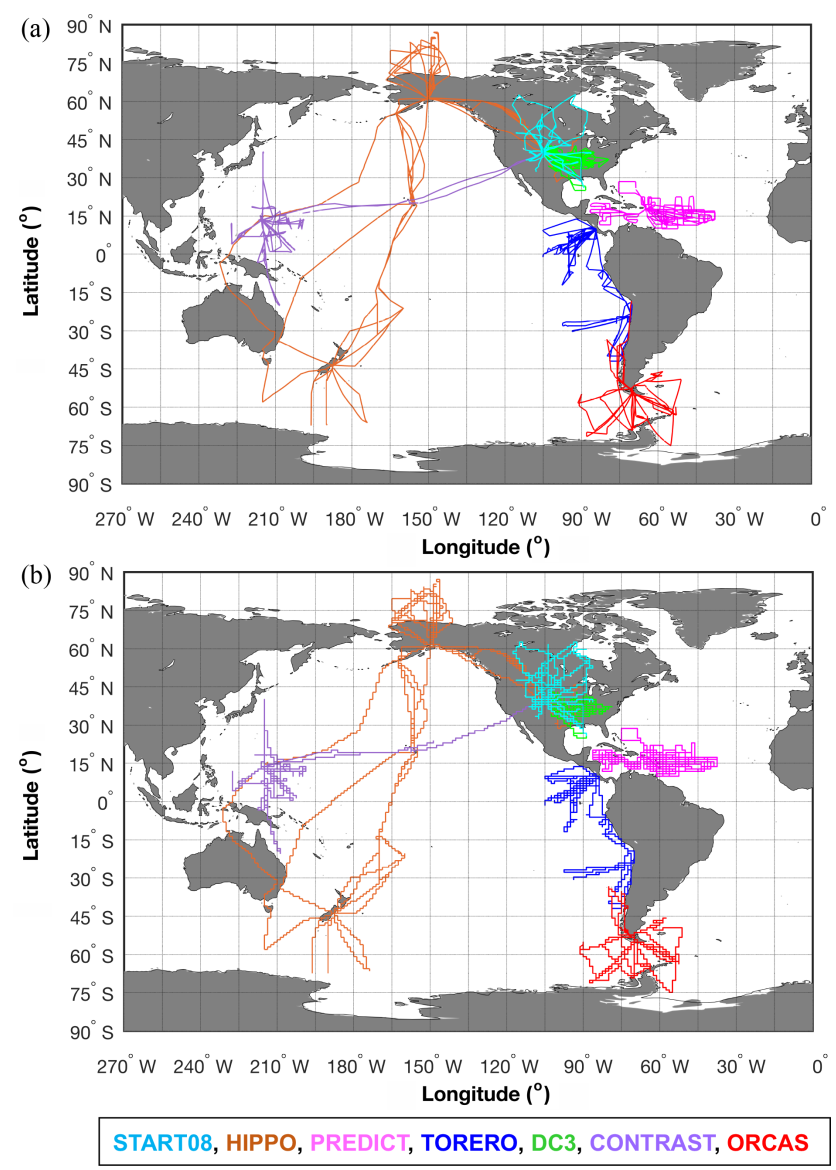

Figure 1. Global maps of flight tracks representing the seven campaigns in this study for (a) in situ observations and (b) CAM6-nudg. Colors denote different campaigns.

observations and the collocated CAM6 nudged simulations (hereafter named "CAM6-nudg" data) are shown in Fig. 1.

For this study, ice particle measurements are provided by the Fast 2-Dimensional Cloud particle imaging probe (Fast2DC) with a 64-diode laser array for a range of $25-1600 \mu \mathrm{m}$. Larger particles can be reconstructed up to $3200 \mu \mathrm{m}$. The mass-dimensional relationship of Brown and Francis (1995) is used to calculate IWC for the Fast-2DC probe, which was previously used in other studies of the Fast-2DC probe aboard the NSF GV aircraft (Diao et al., 2014a, b, 2015). Number-weighted mean diameter $\left(D_{\mathrm{i}}\right)$ is calculated by summing up the size of particles in each bin using the bin center and then dividing it by the total number of particles. In order to mitigate the shattering effect, particles with diameters $<62.5 \mu \mathrm{m}$ (i.e., first two bins) are excluded in the Fast-2DC measurements when calculating IWC, $N_{\mathrm{i}}$ and $D_{\mathrm{i}}$. The Rosemount temperature probe was used for temperature measurements, which has an accuracy and precision of $\sim \pm 0.3$ and $0.01 \mathrm{~K}$, respectively. All analyses are restricted to temperatures $\leq-40^{\circ} \mathrm{C}$, in order to exclude the presence of supercooled liquid droplets in this study. Laboratory calibrated and 
Table 1. Descriptions of seven NSF flight campaigns conducted with the NSF/NCAR GV research aircraft.

\begin{tabular}{|c|c|c|c|c|c|c|c|}
\hline Acronym & Field campaign & Time & $\begin{array}{l}\text { Latitude, longi- } \\
\text { tude }\end{array}$ & Region* & $\begin{array}{r}\begin{array}{r}\text { Flight } \\
\text { hours }\end{array} \\
\text { (all temperatures) }\end{array}$ & $\begin{array}{r}\text { In-cloud } \\
\text { hours } \\
\left(\leq-40^{\circ} \mathrm{C}\right)\end{array}$ & $\begin{array}{r}\text { Clear-sky } \\
\text { hours } \\
\left(\leq-40^{\circ} \mathrm{C}\right)\end{array}$ \\
\hline START08 ${ }^{a, b}$ & $\begin{array}{l}\text { Stratosphere- } \\
\text { Troposphere Analyses } \\
\text { of Regional Transport }\end{array}$ & Apr-Jun 2008 & $\begin{array}{l}26-62^{\circ} \mathrm{N}, 117- \\
86^{\circ} \mathrm{W}\end{array}$ & NM, NP & 84 & 2 & 52 \\
\hline $\mathrm{HIPPO}^{\mathrm{c}-\mathrm{f}}$ & $\begin{array}{l}\text { HIAPER } \\
\text { pole Pole-to- } \\
\text { deployments } 2-5\end{array}$ & $\begin{array}{l}\text { Oct-Nov 2009; } \\
\text { Mar-Apr 2010; } \\
\text { Jun-Jul 2011; } \\
\text { Aug-Sep 2011 }\end{array}$ & $\begin{array}{l}87^{\circ} \mathrm{N}-67^{\circ} \mathrm{S}, \\
128^{\circ} \mathrm{E}-90^{\circ} \mathrm{W}\end{array}$ & A & 333 & 7 & 111 \\
\hline PREDICT $^{\mathrm{g}}$ & $\begin{array}{l}\text { PRE-Depression Inves- } \\
\text { tigation of Cloud Sys- } \\
\text { tems in the Tropics }\end{array}$ & Aug-Sep 2010 & $\begin{array}{l}10-28.5^{\circ} \mathrm{N} \\
86-37^{\circ} \mathrm{W}\end{array}$ & NT & 105 & 25 & 66 \\
\hline $\mathrm{DC} 3^{\mathrm{h}}$ & $\begin{array}{l}\text { Deep Convective } \\
\text { Clouds and Chemistry } \\
\text { Project }\end{array}$ & May-Jun 2012 & $\begin{array}{l}25-42^{\circ} \mathrm{N} \\
106-80^{\circ} \mathrm{W}\end{array}$ & NM & 144 & 23 & 54 \\
\hline TORERO $^{\mathrm{i}}$ & $\begin{array}{l}\text { Tropical Ocean tRopo- } \\
\text { sphere Exchange of Re- } \\
\text { active halogen species } \\
\text { and Oxygenated VOC }\end{array}$ & Jan-Feb 2012 & $\begin{array}{l}42^{\circ} \mathrm{S}-14^{\circ} \mathrm{N} \\
105-70^{\circ} \mathrm{W}\end{array}$ & NT, ST, SM & 125 & 2 & 52 \\
\hline CONTRAST $^{\mathrm{j}}$ & $\begin{array}{l}\text { CONvective TRansport } \\
\text { of Active Species in the } \\
\text { Tropics }\end{array}$ & Jan-Feb 2014 & $\begin{array}{l}20^{\circ} \mathrm{S}-40^{\circ} \mathrm{N} \\
132^{\circ} \mathrm{E}- \\
105^{\circ} \mathrm{W}\end{array}$ & NM, NT, ST & 116 & 23 & 48 \\
\hline ORCAS $^{\mathrm{k}}$ & $\begin{array}{l}\text { The } \mathrm{O}_{2} / \mathrm{N}_{2} \text { Ratio and } \\
\mathrm{CO}_{2} \text { Airborne Southern } \\
\text { Ocean (ORCAS) Study }\end{array}$ & Jan-Mar 2016 & $\begin{array}{l}75-18^{\circ} \mathrm{S} \\
91-51^{\circ} \mathrm{W}\end{array}$ & SM, SP & 95 & 1 & 40 \\
\hline
\end{tabular}

* N, Northern Hemisphere; S, Southern Hemisphere; T, tropics; M, midlatitudes; P, polar regions; A, all regions.

a,b UCAR/NCAR (2009, 2019a). ${ }^{\mathrm{c}-\mathrm{f}}$ UCAR/NCAR (2019b-e). ${ }^{\mathrm{g}}$ UCAR/NCAR (2019f). ${ }^{\mathrm{h}}$ UCAR/NCAR (2018a). ${ }^{\mathrm{i}}$ UCAR/NCAR (2019g). ${ }^{\mathrm{j}}$ UCAR/NCAR (2018b).

${ }^{k}$ UCAR/NCAR (2018c). Full citations of each dataset are included in the reference list.

quality-controlled water vapor data were collected using the vertical-cavity surface-emitting laser (VCSEL) hygrometer (Zondlo et al., 2010), with an accuracy of $\sim 6 \%$ and precision of $\leq 1 \%$. Both temperature and water vapor are used at $1 \mathrm{~Hz}$ resolution for this analysis. Aerosol measurements were collected from the Ultra-High-Sensitivity Aerosol Spectrometer (UHSAS), which uses 100 logarithmically spaced bins ranging from $0.06-1 \mu \mathrm{m}$. RHi is calculated using saturation vapor pressure with respect to ice from Murphy and Koop (2005). The combined RHi uncertainties from the measurements of temperature and water vapor range from $6.9 \%$ at $-40{ }^{\circ} \mathrm{C}$ to $7.8 \%$ at $-78^{\circ} \mathrm{C}$. Measurements are separated by cloud condition where in-cloud condition is defined by the presence of at least one ice crystal from the Fast 2-DC probe $\left(N_{\mathrm{i}}>0 \mathrm{~L}^{-1}\right)$. The same in-cloud definition has been used by several previous studies (D'Alessandro et al., 2017; Diao et al., 2014a, b, 2015, 2017; Tan et al., 2016), and all other samples are defined as clear sky. For regional variation analysis, data are binned by six latitudinal regions in the two hemispheres, that is, $\mathrm{NH}$ polar $\left(60-90^{\circ} \mathrm{N}\right)$, SH polar $(60$ $\left.90^{\circ} \mathrm{S}\right)$, $\mathrm{NH}$ midlatitudes $\left(30-60^{\circ} \mathrm{N}\right)$, SH midlatitudes $(30$ $\left.60^{\circ} \mathrm{S}\right), \mathrm{NH}$ tropics $\left(0-30^{\circ} \mathrm{N}\right)$ and $\mathrm{SH}$ tropics $\left(0-30^{\circ} \mathrm{S}\right)$. The majority of observations in the $\mathrm{SH}$ midlatitude and tropical regions are located over the oceans, while the observations of $\mathrm{NH}$ midlatitude and polar regions are predominantly over land.

The vertical profiles of observed in-cloud temperature, clear-sky potential temperature $(\Theta)$ and their correlations are shown in Fig. 2. The observations sampled temperatures from -78 to $-40{ }^{\circ} \mathrm{C}$ and altitudes from $5-15 \mathrm{~km}$, while a previous study of Krämer et al. (2020) sampled -91 to $-30^{\circ} \mathrm{C}$ and 5-19 km (their Fig. 2). The lowest temperatures are found in the tropical regions and at the highest altitudes, whereas polar regions show more observations at lower altitudes that satisfy temperature $\leq-40^{\circ} \mathrm{C}$. Distributions of cirrus cloud properties (i.e., IWC, $N_{\mathrm{i}}, D_{\mathrm{i}}$ ), in-cloud and clearsky RHi, and clear-sky water vapor mixing ratio for the observation dataset are shown in Fig. 3. $D_{\mathrm{i}}$ increases with decreasing altitudes, IWC slightly increases with decreasing altitudes, and $N_{\mathrm{i}}$ is almost independent of altitudes. Clear-sky $\mathrm{RHi}$ and water vapor mixing ratio both increase with decreasing altitudes, while in-cloud RHi is centered around $100 \%$ and shows smaller dependency on altitudes. Compared with Fig. 3 in Krämer et al. (2020), $48 \%$ of their ice particle samples have $D_{\mathrm{i}}<40 \mu \mathrm{m}$, which is below the size cut-off used in this study. The higher $D_{\mathrm{i}}$ in this study also leads to 

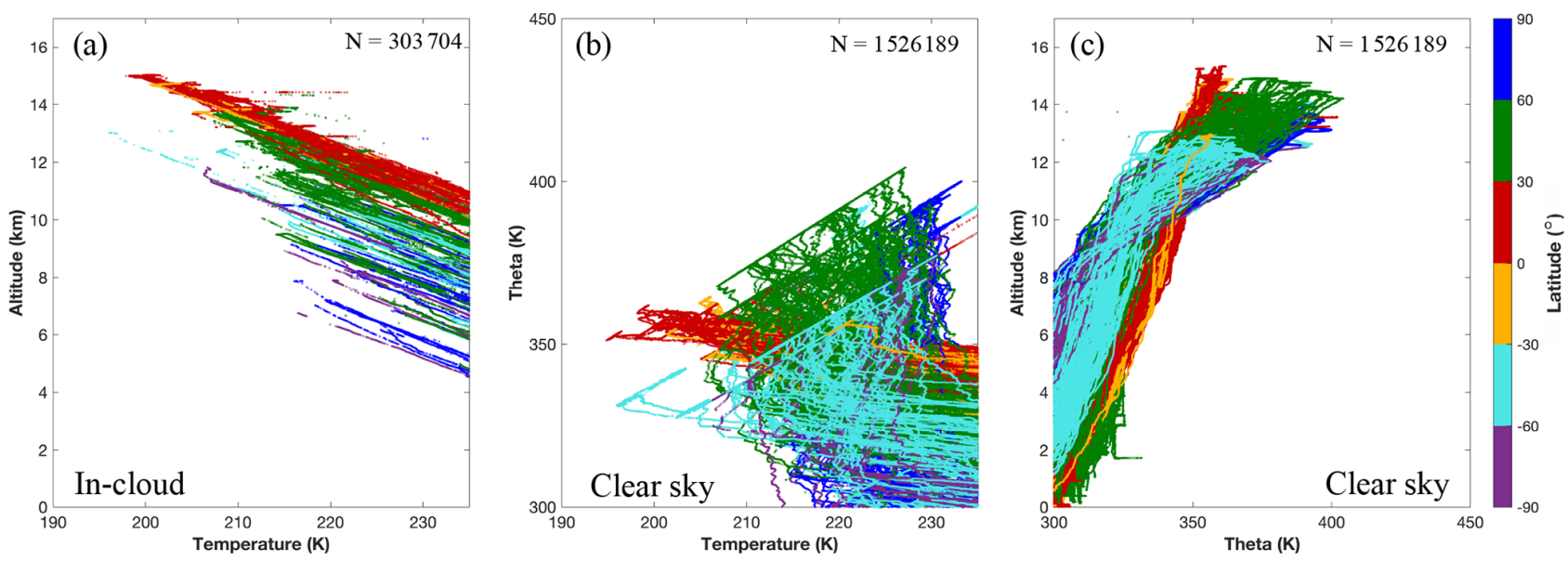

Figure 2. (a) Vertical profiles of temperature, (b) potential temperature vs. temperature and (c) vertical profiles of potential temperature based on in situ observations at temperatures $\leq-40^{\circ} \mathrm{C}$. Number of samples $(N)$ for $1 \mathrm{~Hz}$ observations is shown in the figure legend. Colors denote six latitudinal regions.

lower range of $N_{\mathrm{i}}\left(0.01-1000 \mathrm{~L}^{-1}\right)$ and higher range of IWC $\left(10^{-5}-10 \mathrm{~g} \mathrm{~m}^{-3}\right)$ compared with that previous study (i.e., $N_{\mathrm{i}}$ from $0.1-10^{5} \mathrm{~L}^{-1}$ and IWC from $10^{-7}-1 \mathrm{~g} \mathrm{~m}^{-3}$ ), representing the sampling bias towards larger particles in this study. The relationships of IWC with respect to meteorological conditions (i.e., temperature and RHi) and other microphysical properties (i.e., $N_{\mathrm{i}}$ and $D_{\mathrm{i}}$ ) are shown in Fig. $\mathrm{S} 1$ in the Supplement. The distributions of IWC samples are relatively uniform at various temperature and RHi, while more IWC samples are correlated with $D_{\mathrm{i}}$ between 100 and $300 \mu \mathrm{m}$.

\subsection{Climate model description and experiment design}

This study uses model simulations based on the NCAR CAM6 model. Compared with its previous version (the CAM5 model), CAM6 implemented a new scheme, the Cloud Layers Unified by Binomials (CLUBB) for representations of boundary layer turbulence, shallow convection and cloud macrophysics (Bogenschutz et al., 2013). CLUBB is a higher-order turbulence closure scheme that calculates prognostic higher moments based on joint probability density functions (PDFs) for vertical velocity, temperature and moisture (Golaz et al., 2002). An improved bulk two-moment cloud microphysics scheme has been implemented (Gettelman and Morrison, 2015) that replaces diagnostic treatment of rain and snow with prognostic treatment of all hydrometeors (i.e., rain and snow). This is coupled with a four-mode aerosol model (MAM4) (Liu et al., 2016) for simulations of aerosols and aerosol-cloud interactions. It allows ice crystals to form via homogeneous freezing of sulfate aerosols and heterogeneous nucleation of dust particles (Liu et al., 2007; Liu and Penner, 2005). The model uses Wang et al. (2014b) for ice nucleation, which implemented and improved Hoose et al. (2010) by considering the probability density function of contact angles for the classical nucleation theory. The model also uses Shi et al. (2015) for modifications of preexisting ice. Finally, the deep convection scheme (Zhang and McFarlane, 1995) has been tuned to include sensitivity to convection inhibition.

Results from in situ observations are compared with two types of CAM6 simulations: nudged and free-running simulations. Simulations are based on a finite-volume dynamical core (Lin, 2004) with a horizontal resolution of $0.9^{\circ} \times 1.25^{\circ}$ and 32 vertical levels. All simulations are conducted using prescribed sea-surface temperature and presentday aerosol emissions and include a 6-month spin-up time. CAM6 nudged simulations are nudged spatially and temporally with meteorological data (i.e., 2-D horizontal wind and temperature) from the Modern-Era Retrospective Analysis for Research and Applications version 2 (MERRA2) (Gelaro et al., 2017) and collocated with aircraft flight tracks in space and time. A nudged simulation was conducted for each campaign independently and was combined into one dataset to compare with observations. One free-running simulation was conducted for the duration of all flight campaigns from July 2008 to February 2016. To reduce the size of model output when comparing with observations, a total of 24 instantaneous output data from the free-running simulation are combined into one dataset ("CAM6-free" hereafter), which includes 00:00 and 12:00 UTC for the first day of each month in 2010. Additional sensitivity tests on different model output from the free-running simulation show very minor differences in the statistical distributions of cirrus microphysical properties and the correlations with their controlling factors when selecting different years, seasons and days in a month.

In order to examine observations and simulations on more comparable scales, a running average of $430 \mathrm{~s}$ was calculated for meteorological parameters (i.e., temperature and $\mathrm{RHi}$ ) and microphysical properties (i.e., IWC, $N_{\mathrm{i}}$ and $D_{\mathrm{i}}$ ), which translates to $\sim 100 \mathrm{~km}$ horizontal scales since the mean true 

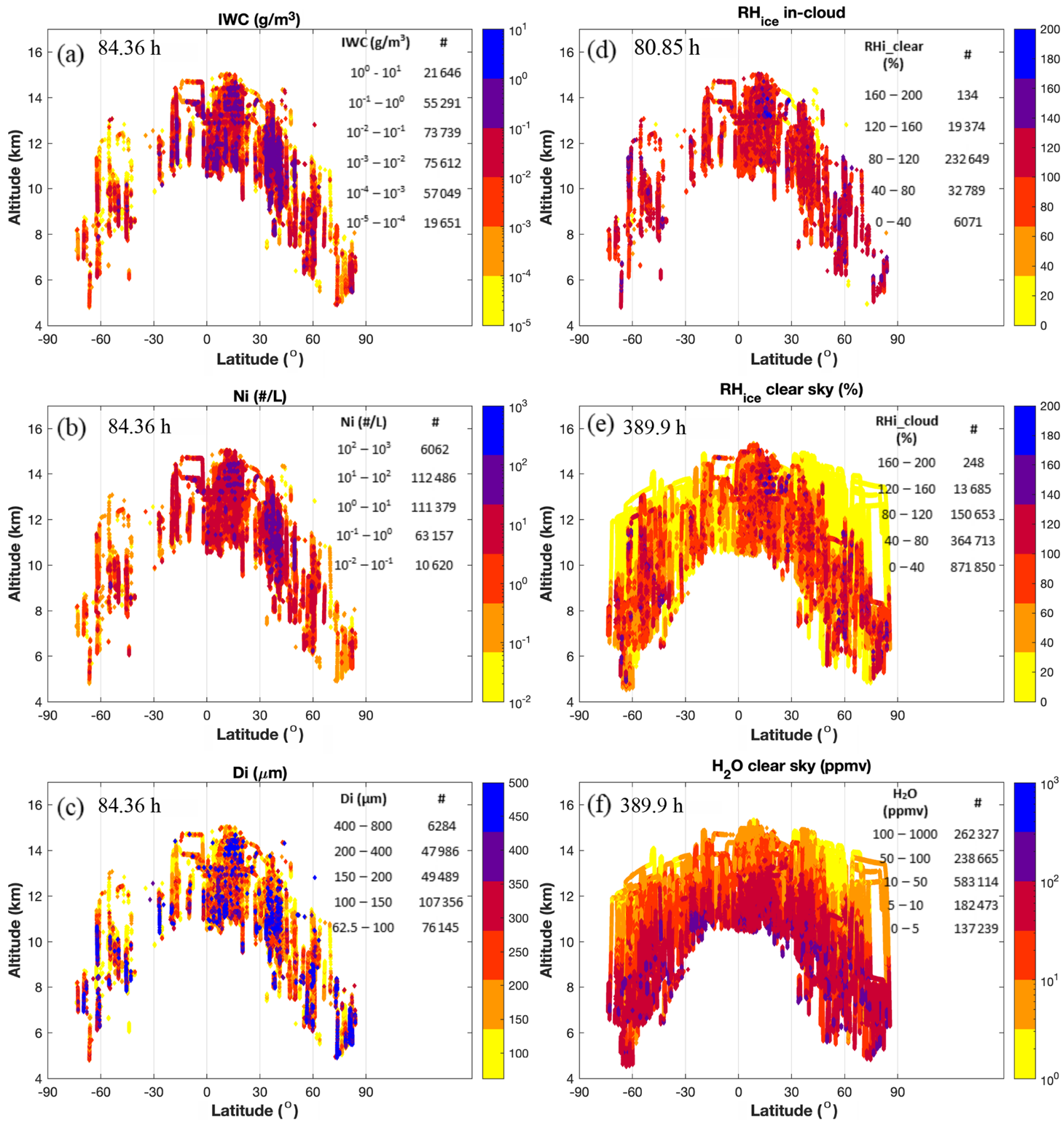

Figure 3. Latitude and altitude distributions of (a) IWC, (b) $N_{\mathrm{i}}$, (c) $D_{\mathrm{i}}$, (d) in-cloud RHi, (e) clear-sky RHi and (f) clear-sky water vapor volume mixing ratio at temperatures $\leq-40^{\circ} \mathrm{C}$. Total measurement hours and number of samples for given intervals are shown for each variable. Note that the measurement ranges shown in the upper right corner are not the full ranges (see Table 2 for the full ranges).

air speed below $-40^{\circ} \mathrm{C}$ for all campaigns was $230 \mathrm{~m} \mathrm{~s}^{-1}$ (Fig. S2). When applying the running average, both in-cloud and clear-sky conditions (i.e., where $N_{\mathrm{i}}$ and IWC values are zero) are included in the averages. Grid-mean quantities from model output are used in comparisons with observations, including "IWC", "NUMICE", "QSNOW" and "NSNOW", which are mass and number concentrations of ice particles and snow, respectively. Another type of comparison between $1 \mathrm{~Hz}$ observations and in-cloud quantities from model output is shown in the Supplement. Both methods have been previously used in model evaluation, such as D'Alessandro et al. (2019), who compared $200 \mathrm{~s}$ averaged aircraft obser- 
vations with simulated grid-mean quantities, and Righi et al. (2020), who compared $1 \mathrm{~Hz}$ aircraft observations with simulated in-cloud quantities.

A summary of the ranges of meteorological conditions and ice microphysical properties for in situ observations and simulations is shown in Table 2. Simulated RHi is calculated from simulated specific humidity and temperature, and the calculation of saturation vapor pressure with respect ice is based on the equation from Murphy and Koop (2005). Simulated ice and snow are restricted to $\geq 62.5 \mu \mathrm{m}$ based on the size cut-off of the Fast-2DC probe by applying methods from Eidhammer et al. (2014). Based on their equations 1 to 5 , we followed their assumption that the shape parameter $\mu$ equals 0 when calculating the slope parameter $\lambda$. Mass and number concentrations of ice and snow are further calculated based on integrals of incomplete gamma functions from $62.5 \mu \mathrm{m}$ to infinity. The simulated values of IWC, $N_{\mathrm{i}}$ and $D_{\mathrm{i}}$ are calculated based on the combined ice and snow population after applying the size restriction. In-cloud conditions in simulations are defined by concurring conditions of IWC $>10^{-7} \mathrm{~g} \mathrm{~m}^{-3}$ and $N_{\mathrm{i}}>10^{-4} \mathrm{~L}^{-1}$ based on size-restricted grid-mean quantities. These thresholds are the lower limits from observations after calculating the $430 \mathrm{~s}$ averages. Note that due to the ice crystal size constraint, some thin cirrus may not be detected. In addition, analysis of simulated cirrus clouds is restricted to similar pressure ranges as those measured in the seven campaigns. An additional constraint on cloud fraction $>10^{-5}$ was applied to both nudged and freerunning simulations to exclude extremely low values.

To visualize the impact of the size truncation on simulated data, we employed methods similar to Gettelman et al. (2020) and reconstructed the simulated particle size distributions for snow and ice in Fig. 4a using gamma functions from Morrison and Gettelman (2008). Compared with the observations, the number density for combined ice and snow is overestimated for smaller particles $(<400 \mu \mathrm{m})$ and underestimated for larger particles $(>1000 \mu \mathrm{m})$. After applying the size restriction, the PDFs of simulated $N_{\mathrm{i}}$ and IWC show increasing probability of small $N_{\mathrm{i}}$ and decreasing probability of small IWC due to the removal of small particles (Fig. 4b and c).

Finally, simulated aerosol number concentrations are further categorized by diameters $>500$ and $>100 \mathrm{~nm}$ (i.e., $N_{\mathrm{a}, 500}$ and $N_{\mathrm{a}, 100}$, respectively), by summing the sizerestricted concentrations of the Aitken, accumulation and coarse aerosol modes. Previously, field experiments found that $N_{\mathrm{a}, 500}$ correlates well with INP number concentrations (DeMott et al., 2010). Even though that correlation was only determined based on observations warmer than $-36^{\circ} \mathrm{C}$, the separation of $N_{\mathrm{a}, 500}$ and $N_{\mathrm{a}, 100}$ can help to examine the effects of larger and smaller aerosols in this work.

\section{Regional variations of cirrus cloud characteristics}

\subsection{Cirrus cloud microphysical properties with respect to temperature}

Three cirrus cloud microphysical properties (IWC, $N_{\mathrm{i}}$ and $\left.D_{\mathrm{i}}\right)$ are examined in relation to temperature at six latitudinal regions (Fig. 5). The standard deviations of the IWC, $N_{\mathrm{i}}$ and $D_{\mathrm{i}}$ in each temperature bin are shown in Fig. S3. The $1 \mathrm{~Hz}$ observations of IWC and $N_{\mathrm{i}}$ in the NH indicate clear latitudinal differences with the highest values occurring in the midlatitudes, followed by tropics, then polar regions for temperatures between -40 and $-60^{\circ} \mathrm{C}$, while for colder temperatures the $\mathrm{NH}$ tropical region shows the highest IWC. In the $\mathrm{SH}$, the highest IWC and $N_{\mathrm{i}}$ occur in the tropics, followed by the polar regions and midlatitudes. Comparing the two hemispheres, IWC and $N_{\mathrm{i}}$ show significant reductions by $\sim 1$ order of magnitude from $\mathrm{NH}$ midlatitudes to $\mathrm{SH}$ midlatitudes (Fig. 5b, e). These hemispheric differences in midlatitudes may be due to air-mass differences between $\mathrm{NH}$ (more continental) and SH (more oceanic) and/or more anthropogenic emissions in the NH. The IWC, $N_{\mathrm{i}}$ and $D_{\mathrm{i}}$ are relatively similar between NH and SH tropical regions, while IWC and $D_{\mathrm{i}}$ are higher in the $\mathrm{SH}$ polar region than in $\mathrm{NH}$ polar regions.

The simulations are further compared with averaged observations at a similar horizontal scale of $\sim 100 \mathrm{~km}$. After applying $430 \mathrm{~s}$ running averages for observations, the average IWC and $N_{\mathrm{i}}$ values decrease by $0.5-1.5$ orders of magnitude compared with $1 \mathrm{~Hz}$ observations depending on temperature and geographical region. Hemispheric differences are mostly consistent between 1 and $430 \mathrm{~s}$ averaged observations except for polar regions. CAM6-nudg data show a similar trend of average IWC, $N_{\mathrm{i}}$ and $D_{\mathrm{i}}$ with respect to temperature as seen in observations; that is, the average IWC increases with increasing temperature, consistent with previous observational studies (Krämer et al., 2016; Luebke et al., 2013; Schiller et al., 2008), average $N_{\mathrm{i}}$ shows no clear trend with temperature, and average $D_{\mathrm{i}}$ increases with increasing temperature. Differing from observations, CAM6 produces the highest IWC and $N_{\mathrm{i}}$ in the tropical regions, followed by midlatitudes, then polar regions for both hemispheres. The simulated IWC, $N_{\mathrm{i}}$ and $D_{\mathrm{i}}$ also show smaller differences between hemispheres and latitudes. The CAM6-nudg data underestimate and overestimate IWC in the NH and SH by $0.5-1$ orders of magnitude, respectively, with the largest discrepancies in the midlatitudes. The simulations overestimate $N_{\mathrm{i}}$ in the tropics and polar regions in both hemispheres by $0.5-1$ orders of magnitude and overestimate $N_{\mathrm{i}}$ in the SH midlatitudes by 1-2 orders of magnitude. The simulated $D_{\mathrm{i}}$ is about half of the observed values in most regions except polar regions. This result indicates "too many" and "too small" simulated ice in most regions. The low bias of simulated $D_{\mathrm{i}}$ indicates possible misrepresentation of ice particle growth and sedimentation in the model parameterization. 
Table 2. Ranges of meteorological conditions and ice microphysical properties for in situ $1 \mathrm{~Hz}$ observations, $430 \mathrm{~s}$ averaged observations, CAM6-nudg and CAM6-free data used in this study.

\begin{tabular}{lllll}
\hline & In situ observations & 430 s averaged observations & CAM6-nudg & CAM6-free \\
\hline$T\left({ }^{\circ} \mathrm{C}\right)$ & -78 to -40 & -77 to -40 & -75 to -40 & -89.9 to -40 \\
$P(\mathrm{~Pa})$ & $12389-53137$ & $37778-53410$ & $12300-53446$ & $12300-53100$ \\
$\mathrm{RHi}(\%)$ in-cloud (clear sky) & $0.99-175.1(0.3-174.9)$ & $0.3-153.7(0.3-134.6)$ & $0.8-159.8(0.05-107.6)$ & $0.003-257.2(0.001-181.4)$ \\
IWC $\left(\mathrm{g} \mathrm{m}^{-3}\right)$ & $0.00004-23.31$ & $1 \times 10^{-7}-11.58$ & $1 \times 10^{-7}-0.12$ & $1 \times 10^{-7}-0.16$ \\
$N_{\mathrm{i}}\left(\mathrm{L}^{-1}\right)$ & $0.039-542.15$ & $9.6 \times 10^{-5}-188.7$ & $1 \times 10^{-4}-207.04$ & $1 \times 10^{-4}-516.7$ \\
$D_{\mathrm{i}}(\mu \mathrm{m})$ & $62.5-3200$ & $62.5-2175$ & $62.5-2062$ & $66.7-2556$ \\
\hline
\end{tabular}

A sensitivity test is conducted by comparing $1 \mathrm{~Hz}$ observations with in-cloud quantities from model output (Fig. S4). Larger differences are seen between simulated and observed IWC and $N_{\mathrm{i}}$ in Fig. S4 compared with Fig. 5. The directions (i.e., positive or negative) of model biases of IWC, $N_{\mathrm{i}}$ and $D_{\mathrm{i}}$ are generally consistent in both comparisons.

A previous study by Righi et al. (2020) evaluated the ice microphysical properties in the EMAC-MADE3 aerosolclimate model (i.e., ECHAM/MESSy Atmospheric Chemistry - Modal Aerosol Dynamics model for Europe adapted for global applications, third generation) by comparing incloud quantities from model output with $1 \mathrm{~Hz}$ in situ observations of multiple aircraft field campaigns from $75^{\circ} \mathrm{N}$ to $25^{\circ} \mathrm{S}$ (Krämer et al., 2009, 2016, 2020). Although that study included a greater number of smaller ice particles (3$1280 \mu \mathrm{m})$ compared with this study, they still showed low biases of simulated $D_{\mathrm{i}}$ at 190-243 K and low biases of simulated IWC at 205-235 K, as well as high biases of simulated $N_{\mathrm{i}}$ above $225 \mathrm{~K}$, which are generally in the same direction as the biases we found in CAM6 model. Note that Righi et al. (2020) implemented different cloud microphysics parameterizations compared with the CAM6 model, including a two-moment cloud microphysics scheme of Kuebbeler et al. (2014) and the ice nucleation parameterization for cirrus clouds ( $T<238.15 \mathrm{~K}$ ) from Kärcher et al. (2006), which account for both homogeneous and heterogeneous nucleation and the competition between the two mechanisms. Additional future intercomparison studies of these models are warranted to examine the reasons behind the similar biases.

\subsection{RHi and $\sigma_{w}$ distributions for in-cloud and clear-sky conditions}

Regional distributions of RHi for clear-sky and in-cloud conditions are shown for $1 \mathrm{~Hz}$ observations (Fig. 6), $430 \mathrm{~s}$ averaged observations (Fig. 7) and simulations (Fig. 8). The $1 \mathrm{~Hz}$ observations show RHi magnitudes ranging from $<5 \%$ up to $\sim 180 \%$ in both clear-sky and in-cloud conditions, and are mostly located below the homogeneous freezing line except for the NH tropical region. A few samples exceed the liquid saturation line but are within the measurement uncertainties of RHi. This result agrees with the RHi distributions based on previous midlatitudinal observations (Cziczo et al.,
2013). Differing from $1 \mathrm{~Hz}$ observations, $430 \mathrm{~s}$ averaged observations show much lower RHi magnitudes for both clearsky and in-cloud conditions, ranging from $<5 \%$ to $120 \%$ $140 \%$. For clear-sky conditions, the majority of the observed and simulated RHi values are below $100 \%$, while the CAM6nudg data show fewer RHi exceeding ice saturation. For in-cloud conditions, both $1 \mathrm{~Hz}$ observations and simulations show that RHi frequently occur within $\sim 20 \%$ of ice saturation, consistent with previous observation and modeling studies (Diao et al., 2014a, 2017; D’Alessandro et al., 2017, 2019; Krämer et al., 2009), while almost no simulated RHi data exceed the homogeneous freezing threshold. The higher RHi observed in the NH tropical region was also observed by Krämer et al. (2009). Such features can be explained by the competition between higher updrafts seen in the tropics and the depletion of water vapor from newly nucleated ice particles as discussed in Kärcher and Lohmann (2002). For the polar regions, in-cloud RHi is skewed towards ISS in both observations and simulations, indicating less effective water vapor depletion likely due to lower $N_{\mathrm{i}}$ values (Fig. 5e). Note that the simulation samples in the tropical regions show peak frequencies at certain temperatures due to larger bin sizes of pressure levels in the lower latitudes.

Regional distributions of the variance of $w\left(\sigma_{w}\right)$ for $1 \mathrm{~Hz}$ observations at 40 and 430 s scales and CAM6 nudged simulations are shown in Figs. 9, 10 and 11, respectively. $\sigma_{w}$ in the observations is calculated as the variance of $w$ within each 40 and $430 \mathrm{~s}$ of data, which correspond to a horizontal scale of $\sim 10$ and $100 \mathrm{~km}$, respectively. The $\sigma_{w}$ in simulations is based on the " $w_{\text {sub }}$ " variable, which is calculated from the square root of turbulent kinetic energy (TKE) (Gettelman et al., 2010). Observed $\sigma_{w}$ shows the highest values in the tropical and midlatitude regions, reaching up to $\sim 3 \mathrm{~ms}^{-1}$, while the polar regions show updrafts up to $\sim 1 \mathrm{~ms}^{-1}$. A similar decreasing trend of maximum $\sigma_{w}$ is seen in the simulations from the lower to higher latitudes. The observations show similar $\sigma_{w}$ maximum values between clear-sky and in-cloud conditions, while the simulations show much higher maximum $\sigma_{w}$ for in-cloud conditions in the tropics $\left(1 \mathrm{~ms}^{-1}\right)$, midlatitude $\left(1 \mathrm{~ms}^{-1}\right)$ and polar regions $\left(0.5 \mathrm{~ms}^{-1}\right)$, compared with those values in clear sky (i.e., 0.5, 0.25 and $0.1 \mathrm{~m} \mathrm{~s}^{-1}$, respectively). This result suggests that the model has a stronger dependence on higher $\sigma_{w}$ for cirrus cloud for- 

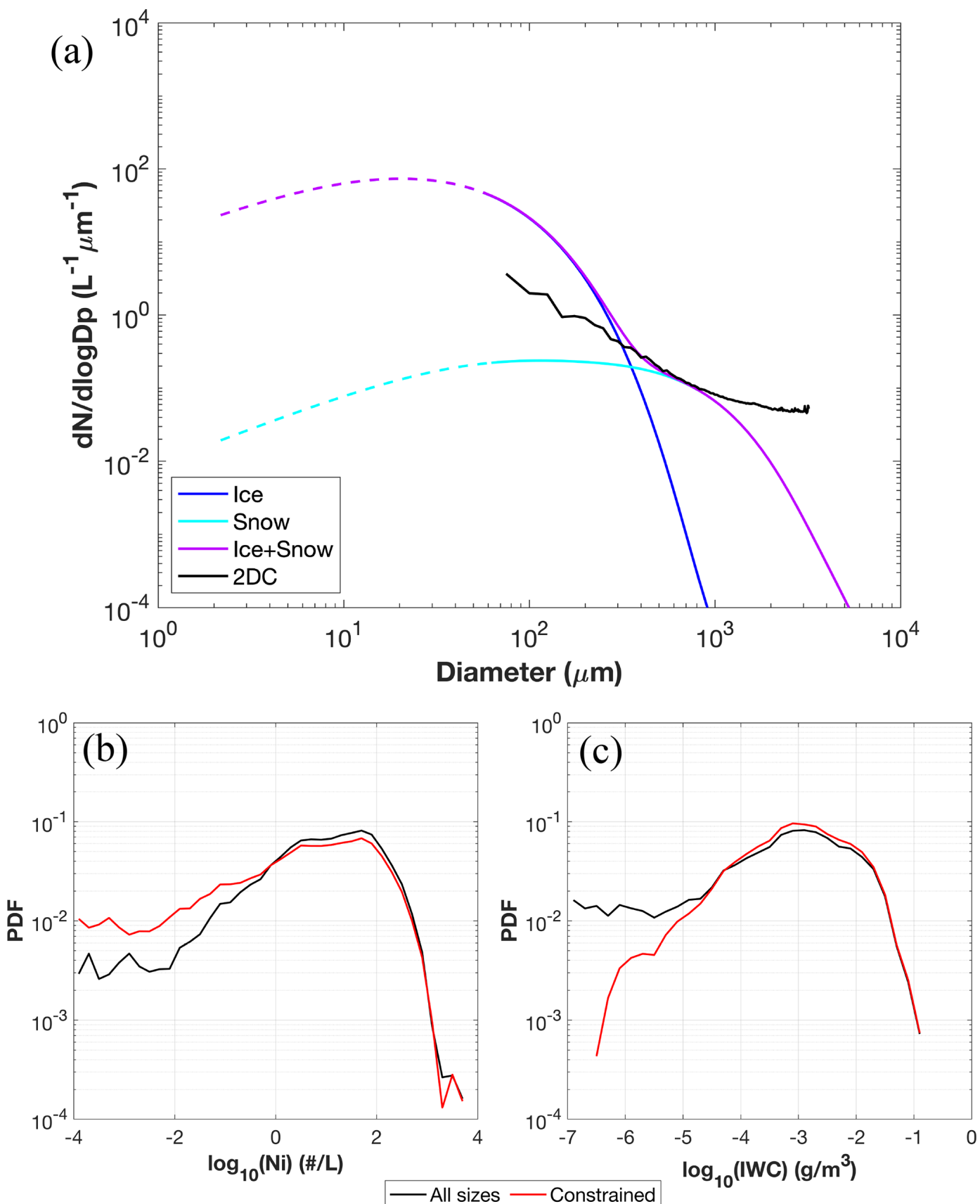

Figure 4. (a) Observed size distribution (black line) and reconstructed size distributions from simulated ice (blue) and snow (cyan). Size truncations to diameters $<62.5 \mu \mathrm{m}$ (dashed lines) are shown for simulated hydrometeors, while the remaining particles $(\geq 62.5 \mu \mathrm{m})$ (solid lines) are used for comparisons with observations. Size distributions for combined ice and snow in the simulations (purple) are also shown before and after the size restriction. Panels (b) and (c) show PDFs of $N_{\mathrm{i}}$ and IWC in the simulation before and after size truncation.

mation compared with observations. We further examine the potential impact of convection in simulations and observations. Figure $\mathrm{S} 5$ shows the locations where $w>1 \mathrm{~m} \mathrm{~s}^{-1}$ is seen in the observations as well as where $w_{\text {sub }}>0.5 \mathrm{~m} \mathrm{~s}^{-1}$ is seen in the CAM6-nudg data for in-cloud conditions. Since $w_{\text {sub }}$ in CAM6 is based on the turbulent scheme, higher $w_{\text {sub }}$ values indicate that the convection scheme may be active and produce detrained ice in convective outflows. The majority of observed and simulated in-cloud samples do not appear to have high $w$ or $w_{\text {sub }}$, indicating that detrained ice from the convection is unlikely a significant contribution. More future investigation is needed to track cirrus cloud origins and quantify impacts from convection. 

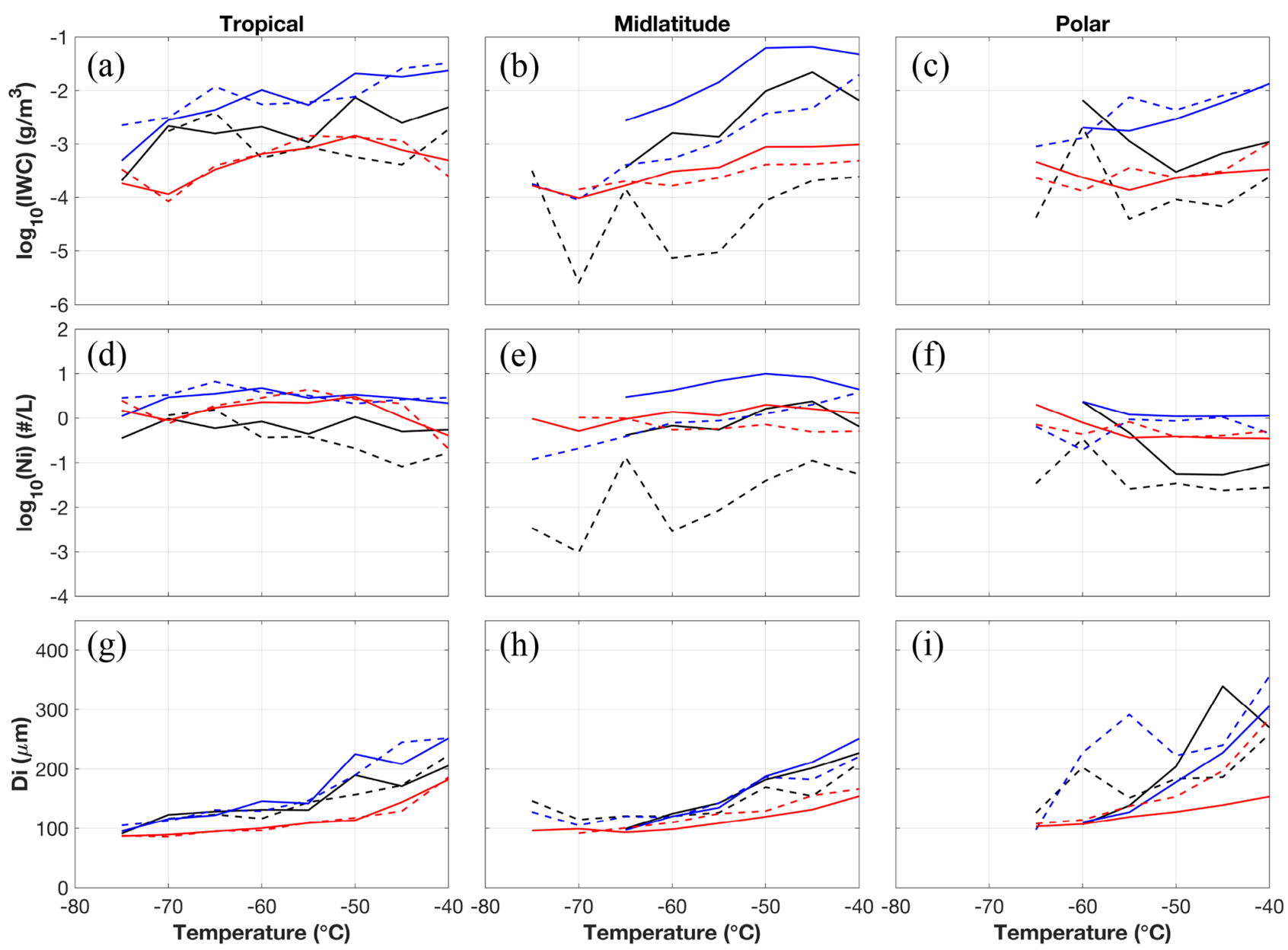

- 1- Hz In situ NH - - - 1- Hz In situ SH — 430-s averaged NH - - - 430-s averaged SH — CAM6 NH - - CAM6 SH

Figure 5. Geometric means of (a-c) IWC and (d-f) $N_{\mathrm{i}}$, as well as $(\mathbf{g}-\mathbf{i})$ linear averages of $D_{\mathrm{i}}$ at $5{ }^{\circ} \mathrm{C}$ temperature intervals between -80 and $-40^{\circ} \mathrm{C}$, compared between $1 \mathrm{~Hz}$ in situ observations (blue lines), $430 \mathrm{~s}$ averaged observations (black lines) and CAM6-nudg (red lines). Observed and simulated microphysical properties are binned by six latitudinal regions, where $\mathrm{NH}$ is denoted by solid lines, and $\mathrm{SH}$ is denoted by dashed lines. The number of samples for $1 \mathrm{~Hz}$ observations at temperatures $\leq-40^{\circ} \mathrm{C}$ in the Northern (Southern) Hemisphere tropical, midlatitude and polar regions are 173930 (15 569), 100615 (3809) and 6704 (2606), respectively. The number of samples for $430 \mathrm{~s}$ averaged observations in these regions are 355082 (40 683), 233546 (26 850) and 24083 (10 252), respectively. The number of samples for CAM6-nudg data in these regions are 3241592 (653 110), 2052353 (590503) and 478844 (209662), respectively.

\section{Individual impacts of key controlling factors on cirrus clouds}

\subsection{Probability density functions of temperature, RHi and $\sigma_{w}$}

PDFs of temperature, RHi and $\sigma_{w}$ are shown in Fig. 12. The PDFs are normalized by the total number of samples of both clear-sky and in-cloud conditions. The observations are located mostly around -68 to $-40^{\circ} \mathrm{C}$, and the simulations show similar temperature distributions. For the PDFs of RHi, the observations and simulations all show a peak position around $100 \%$ for in-cloud condition. However, a secondary peak is shown in simulations at $80 \% \mathrm{RHi}$, which is likely due to the parameter of $\mathrm{RHi}_{\text {min }}$ for ice cloud fraction calculation being set at $80 \%$ for representing variance of humidity in a grid box (more details on $\mathrm{RHi}_{\min }$ are described in Gettelman et al., 2010). In addition, the maximum RHi values for in-cloud conditions are $170 \%, 154 \%, 160 \%$ and $257 \%$ for $1 \mathrm{~Hz}$ observations, $430 \mathrm{~s}$ averaged observations, CAM6-nudg and CAM6-free, respectively. The maximum RHi values for clear-sky conditions are $175 \%, 135 \%, 108 \%$ and $181 \%$, respectively. The CAM6-free data show higher maximum RHi values than CAM6-nudg data, likely due to additional data from tropical regions at temperatures below $-70^{\circ} \mathrm{C}$ (Fig. 12j). When using a lower size cut-off $(1 \mu \mathrm{m})$ of ice particles for the simulation data, the number of in-cloud samples increases by $4 \%$ (Fig. S6). However, negligible dif- 

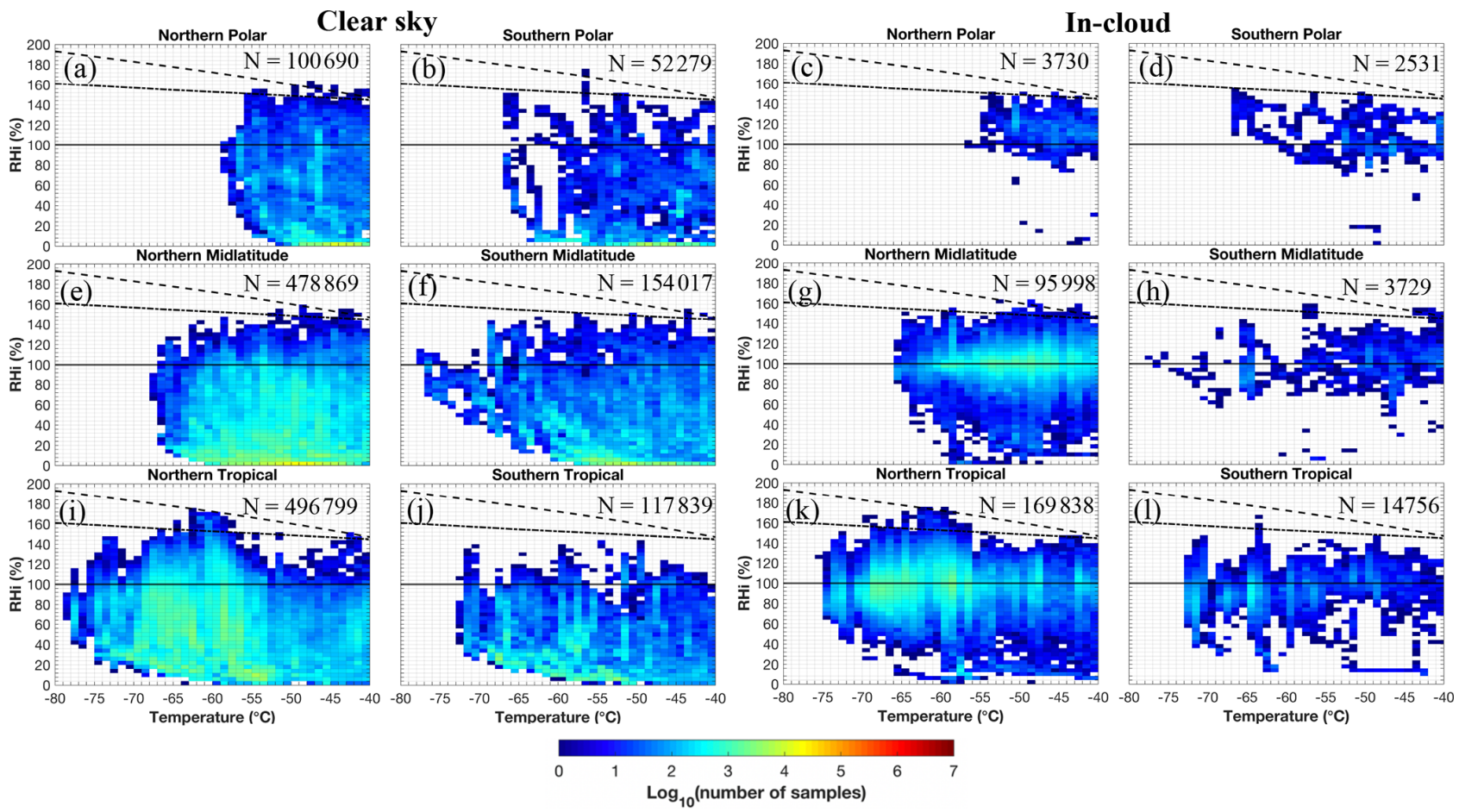

Figure 6. Distributions of RHi at various temperatures and geographical locations from in situ observations under (two left columns) clear-sky and (two right columns) in-cloud conditions. Solid and dashed black lines represent ice and liquid saturation, calculated based on saturation vapor pressure with respect to ice and liquid from Murphy and Koop (2005), respectively. Dash-dotted line denotes the homogeneous freezing threshold for $0.5 \mu \mathrm{m}$ aerosols based on Koop et al. (2000).
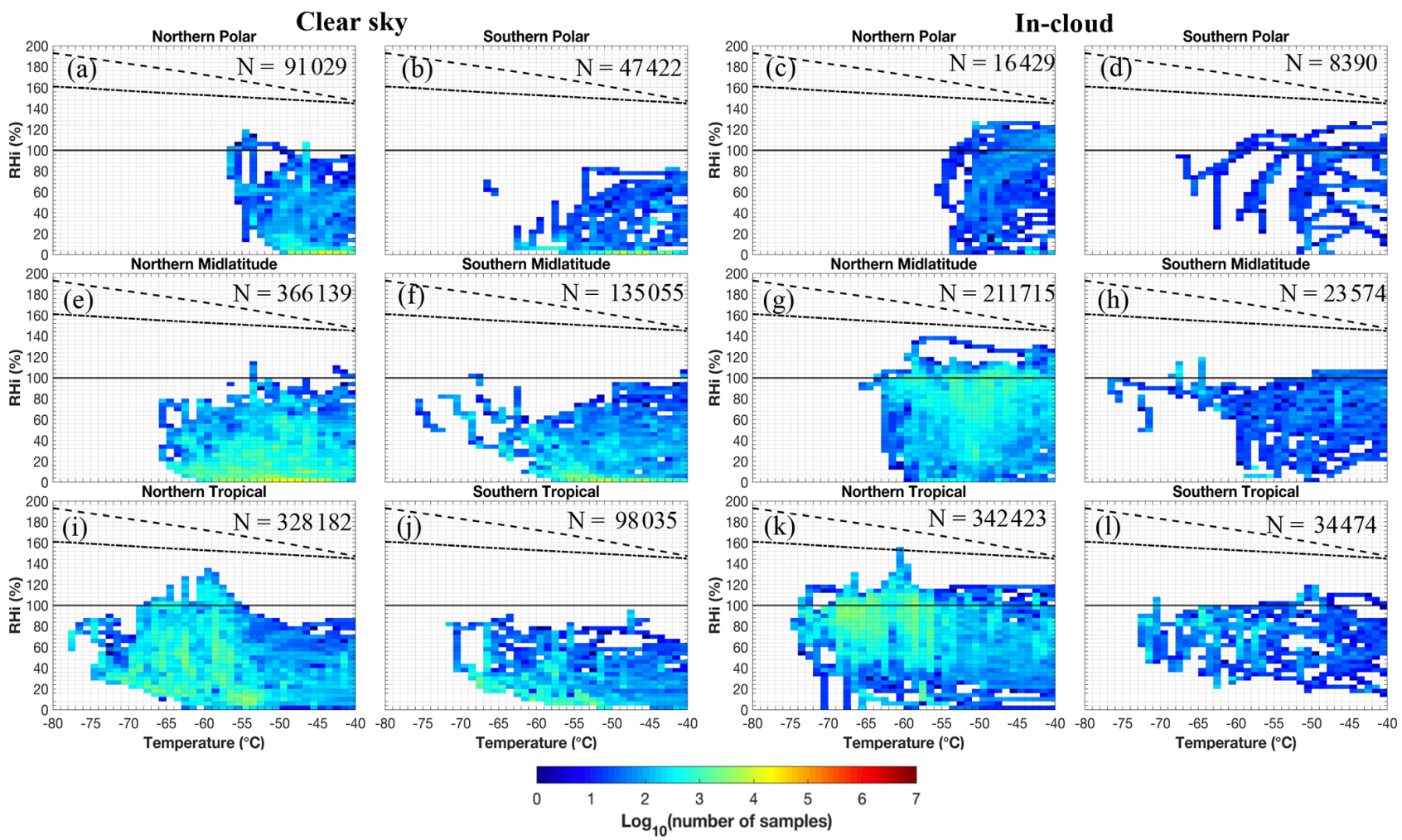

Figure 7. Similar to Fig. 6 but for 430 s scale. 

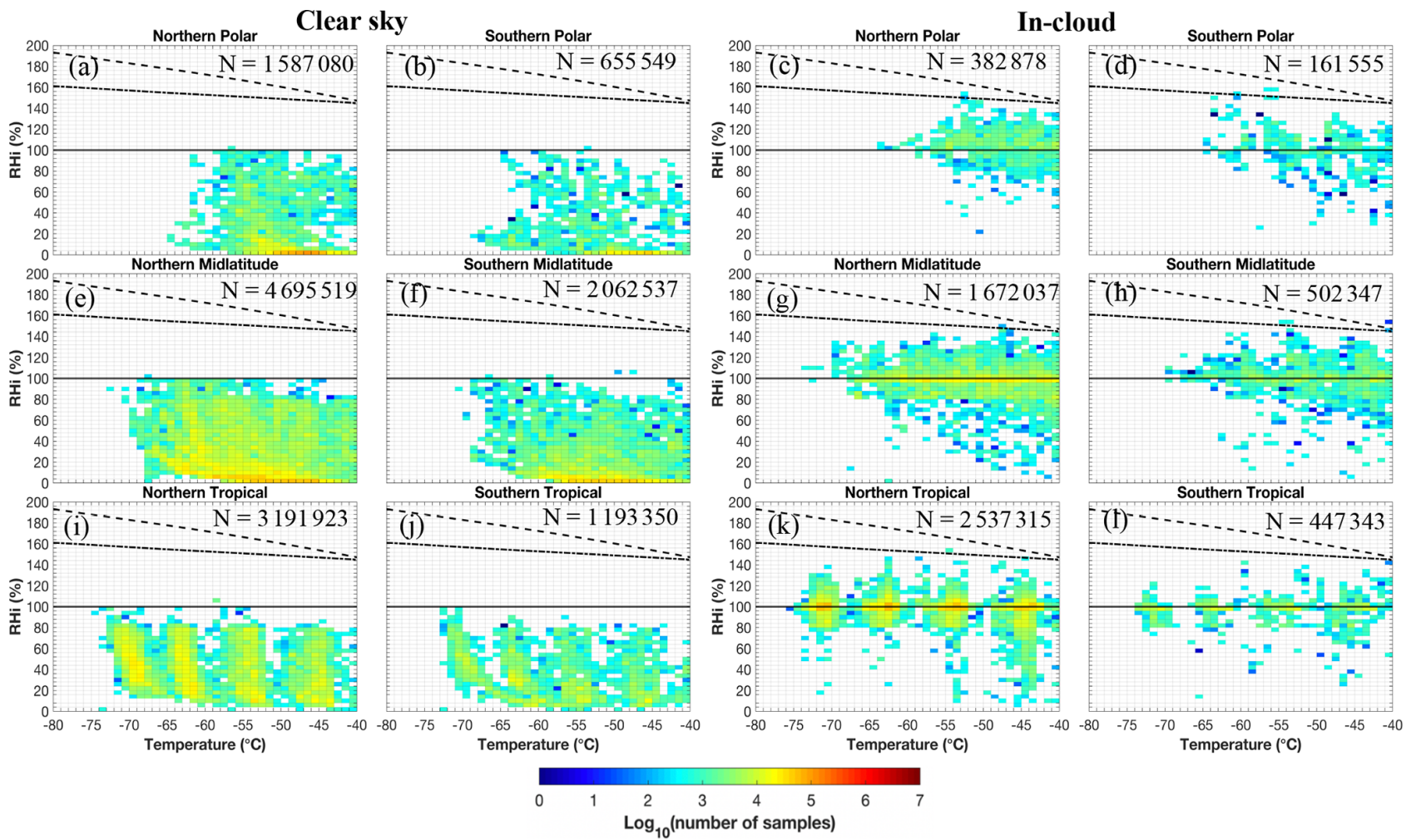

Figure 8. Similar to Fig. 6 but for CAM6-nudg data. RHi values for simulations are calculated using simulated specific humidity and temperature, based on the equation of saturation vapor pressure with respect to ice from Murphy and Koop (2005).

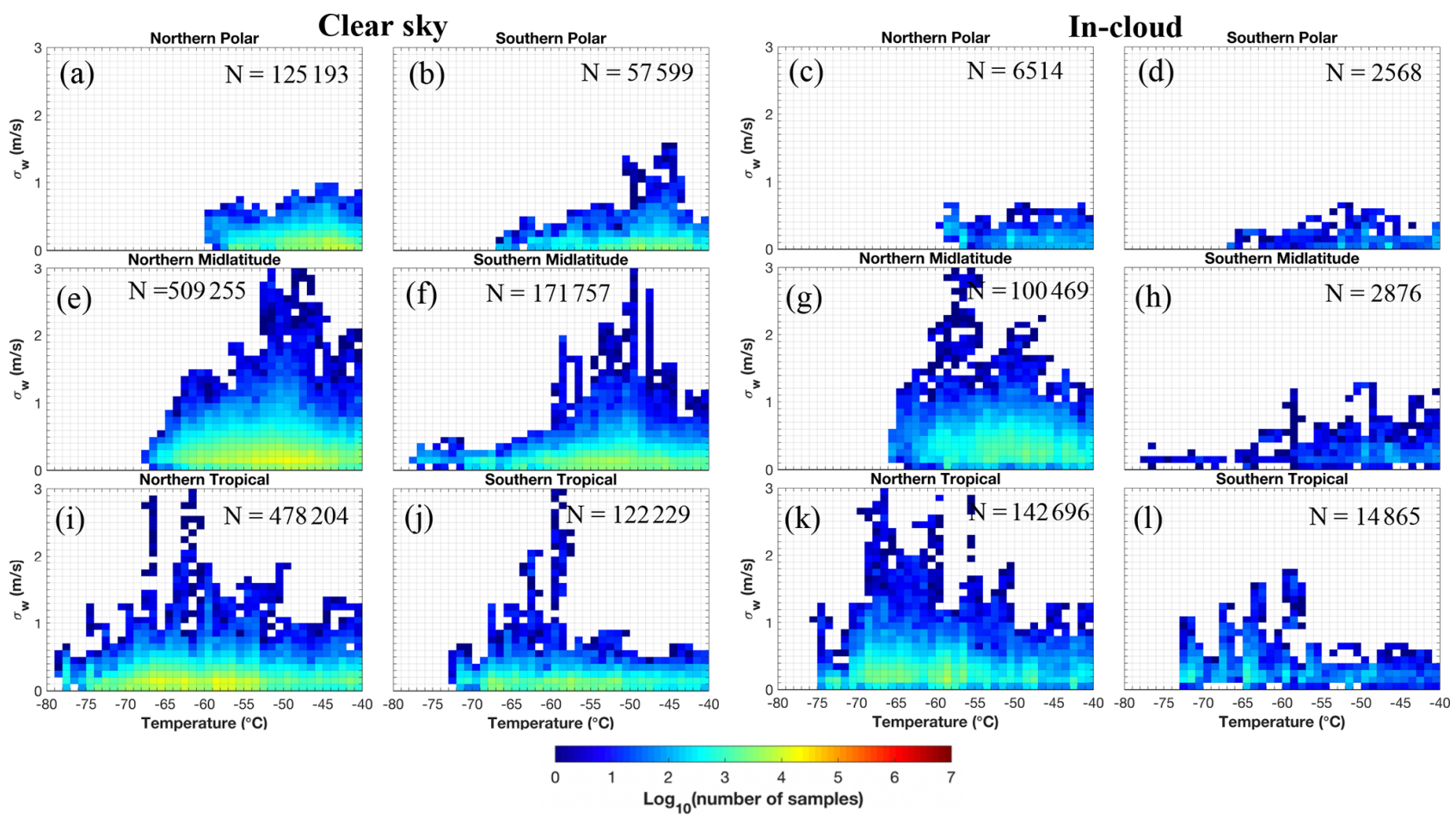

Figure 9. Distributions of $\sigma_{w}$ calculated for every $40 \mathrm{~s}$ using the $1 \mathrm{~Hz}$ observations under (two left columns) clear-sky and (two right columns) in-cloud conditions. 


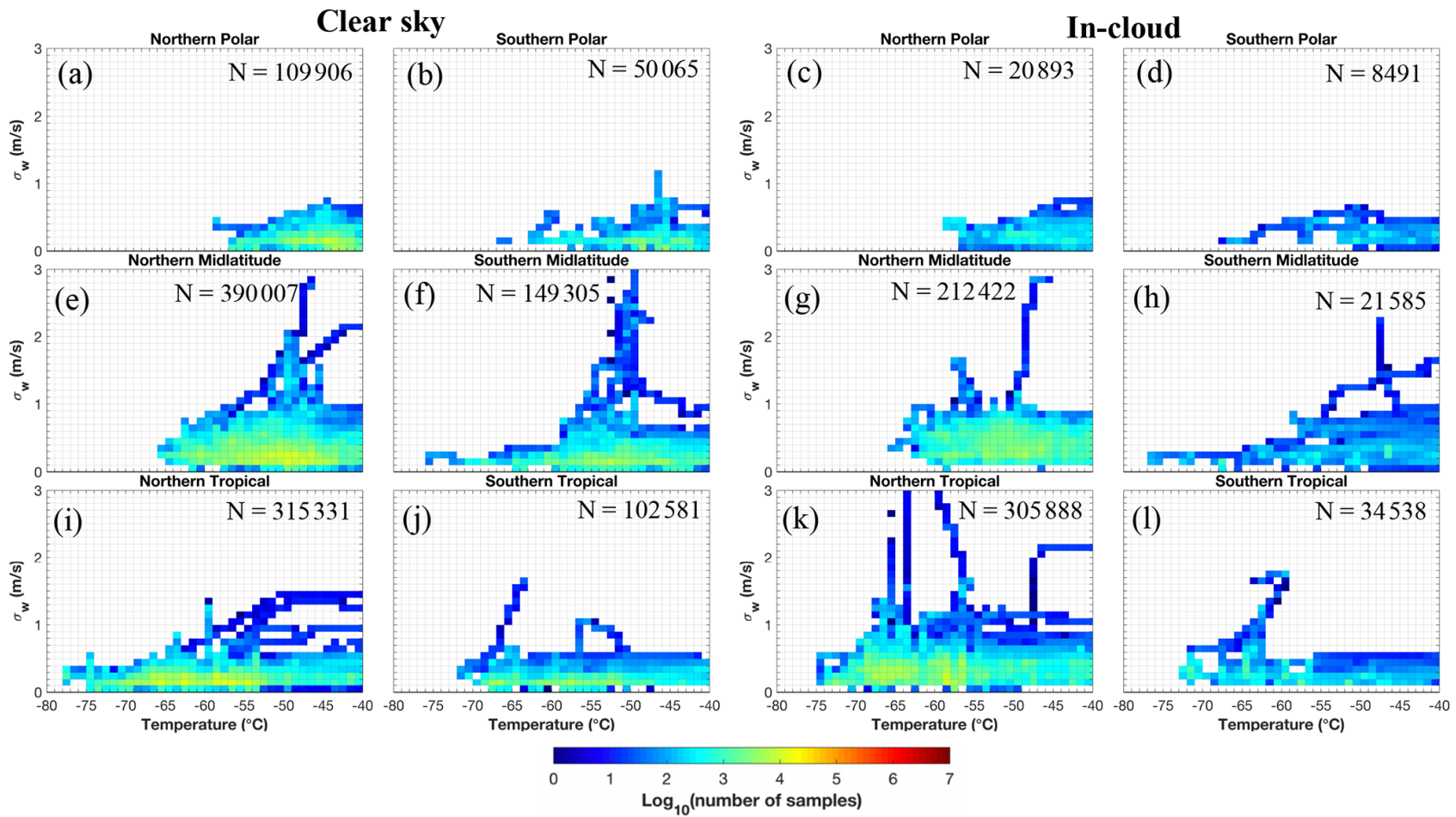

Figure 10. Similar to Fig. 9 but for $430 \mathrm{~s}$ averaged observations.

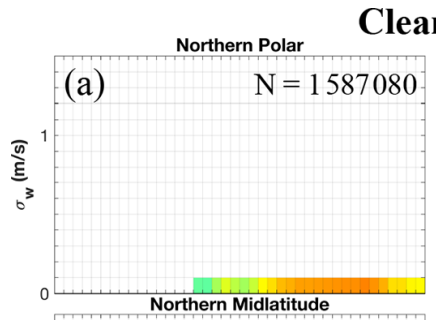

(e) $\quad \mathrm{N}=4695519$

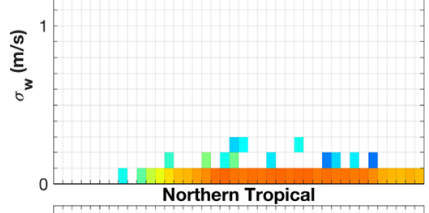

(i)

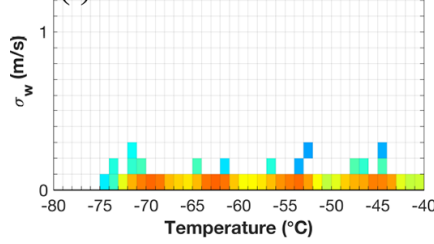

Southern Polar

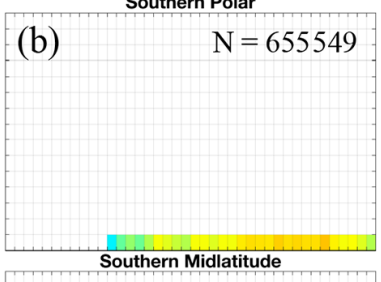

(f) $\quad \mathrm{N}=2062537$
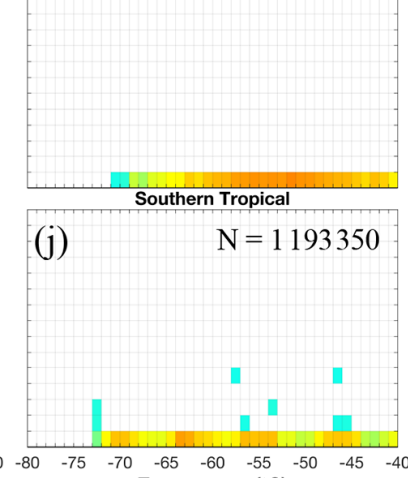

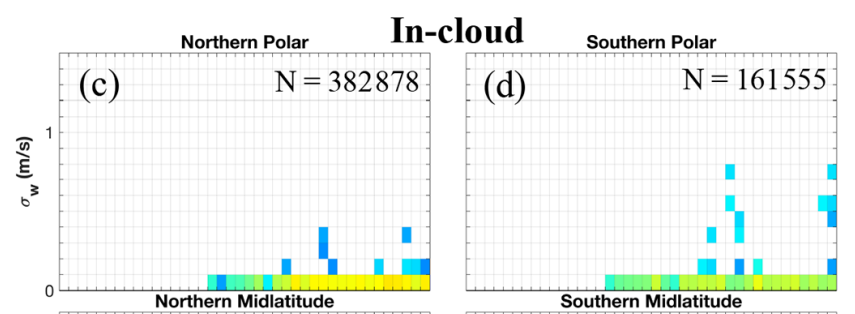

(g)

$\mathrm{N}=1672037$

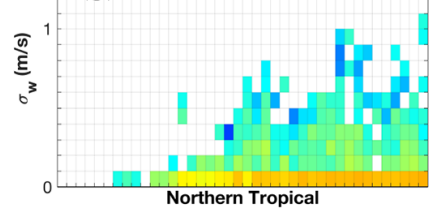

(k)

$\mathrm{N}=2537315$
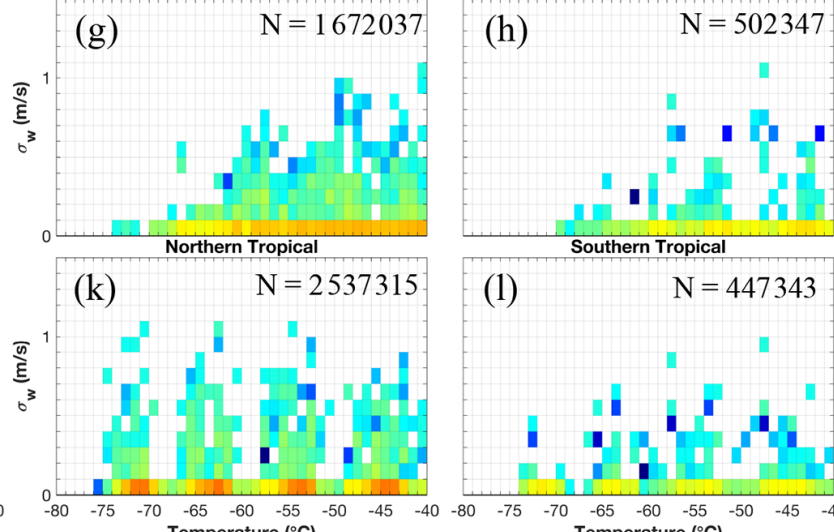

(1)

$\mathrm{N}=447343$

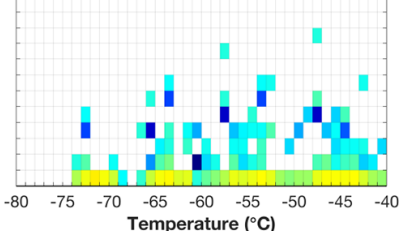

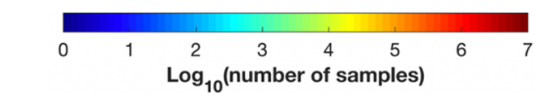

Figure 11. Similar to Fig. 9 but for the CAM6-nudg data. 

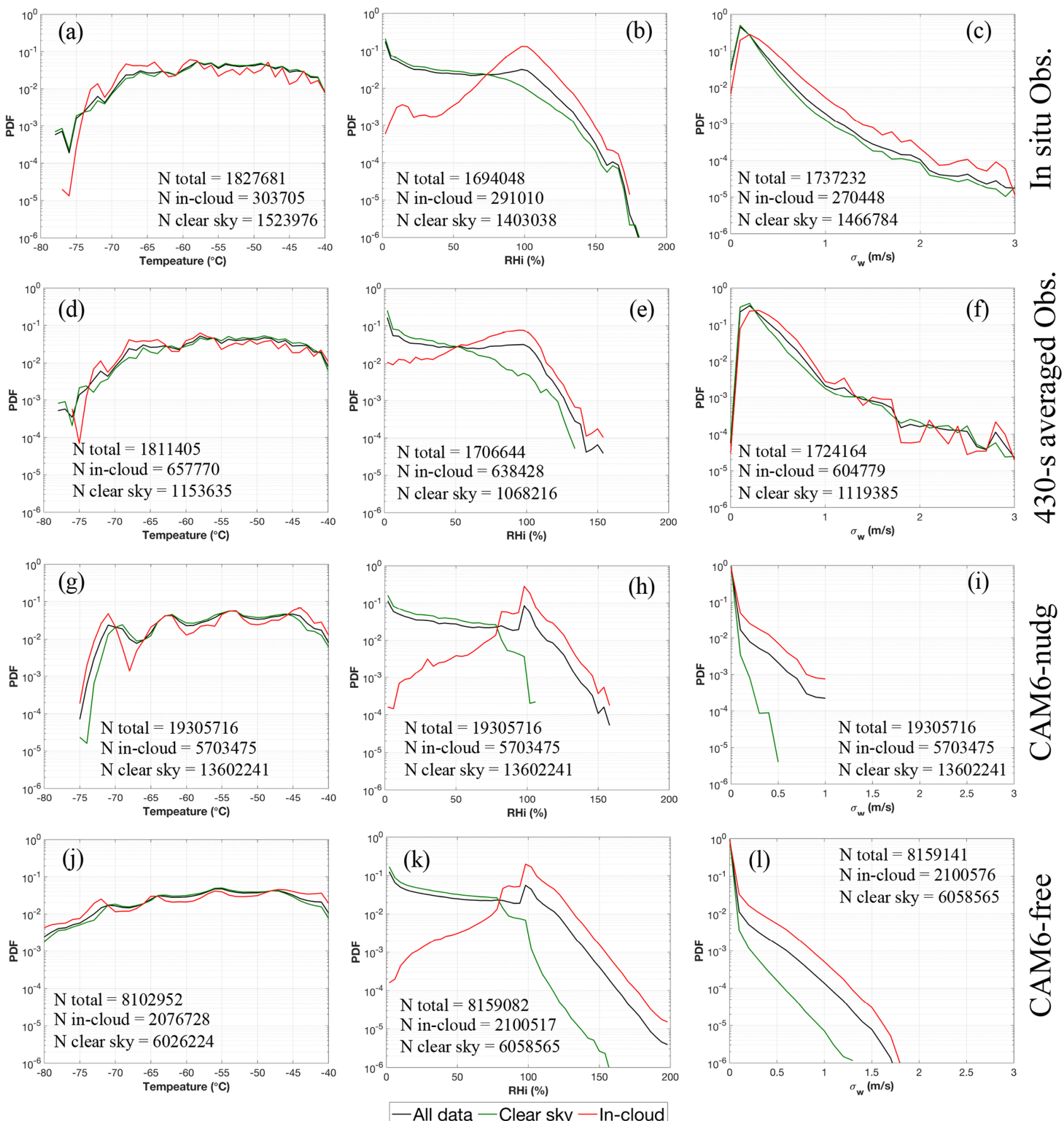

Figure 12. Probability density functions (PDFs) for (a, d, $\mathbf{g}, \mathbf{j})$ temperature, (b, e, h, k) RHi and (c, f, i, l) $\sigma_{w}$, compared among (a-c) $1 \mathrm{~Hz}$ observations, (d-f) $430 \mathrm{~s}$ averaged observations, (g-i) CAM6-nudg and (j-l) CAM6-free data. Note that $\sigma_{w}$ in panel (c) is calculated for every $40 \mathrm{~s}$.

ferences are seen in the PDFs of temperature, RHi and $\sigma_{w}$ for the two simulations between Figs. 12 and S6.

PDFs of $\sigma_{w}$ show consistent results with Figs. 9-11, with simulations showing much higher maximum $\sigma_{w}$ for incloud conditions than clear-sky conditions, while observations show similar maximum $\sigma_{w}$ in both conditions. The lower maximum values of $\sigma_{w}$ in simulations are most likely a result of the model missing representations of gravity waves from topography, fronts and convection, and only including $\sigma_{w}$ from turbulence. 

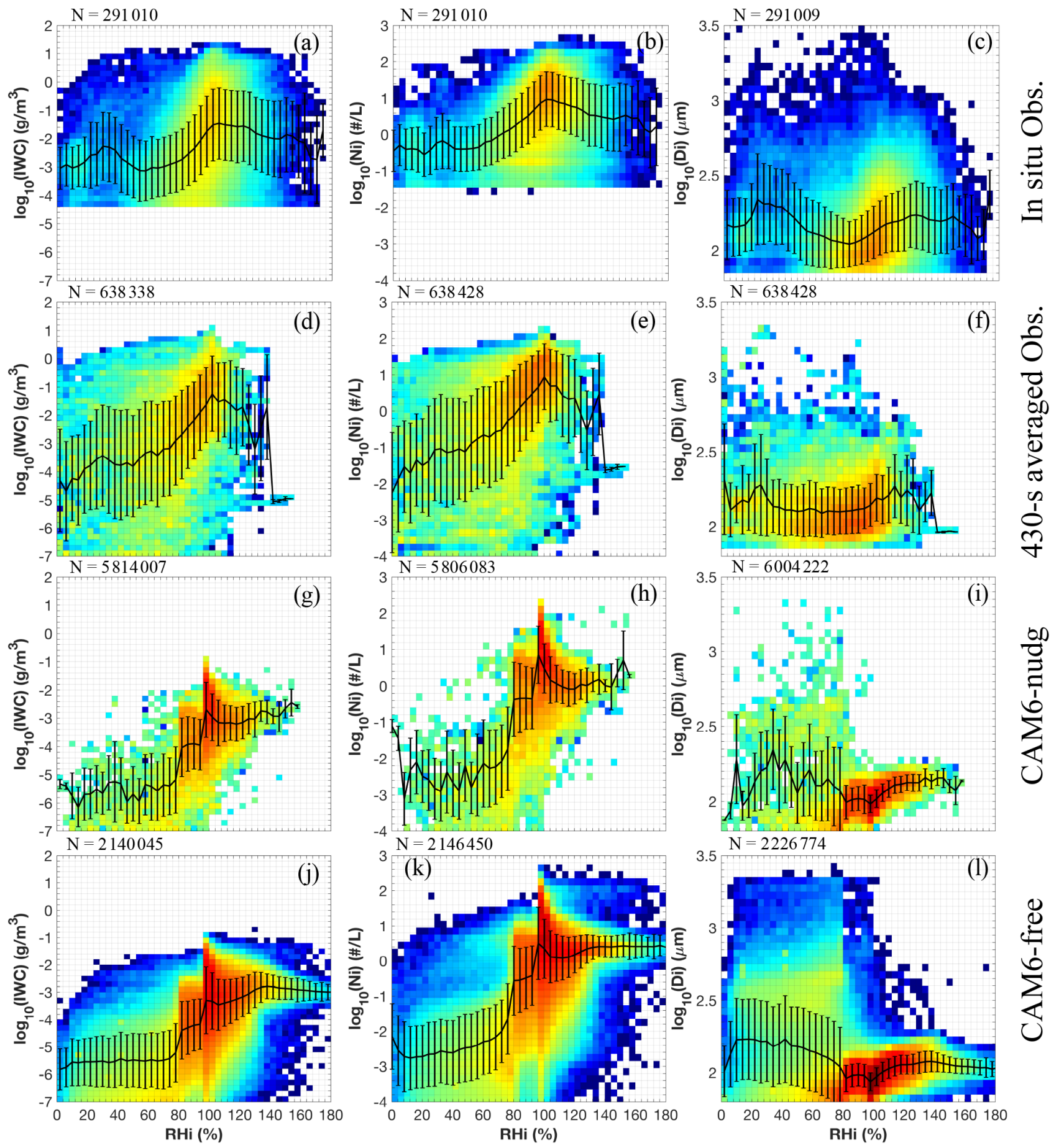

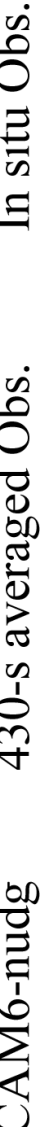
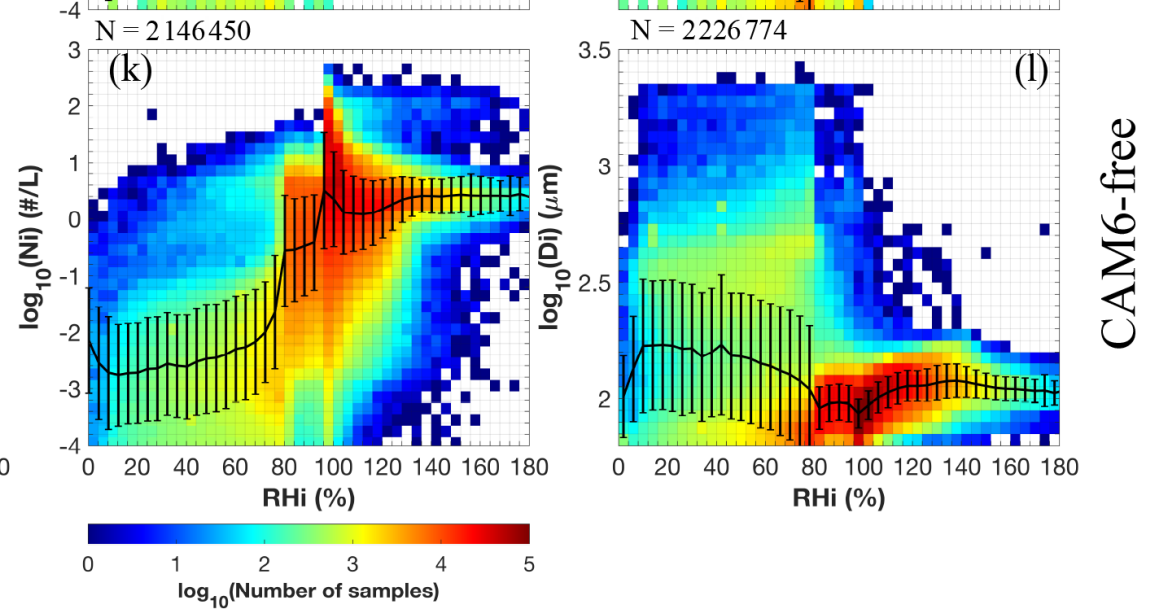

Figure 13. Correlations between RHi and in-cloud IWC, $N_{\mathrm{i}}$ and $D_{\mathrm{i}}$ (columns 1-3, respectively), compared among (a-c) in situ $1 \mathrm{~Hz}$ observations, (d-f) $430 \mathrm{~s}$ averaged observations, (g-i) CAM6-nudg and (j-l) CAM6-free data. Black lines and whiskers denote geometric means and standard deviations, respectively. 


\subsection{Effects of RHi and $\sigma_{w}$ on ice microphysics}

The relationships between ice microphysical properties and RHi are examined in Fig. 13. For the $1 \mathrm{~Hz}$ observations, the maximum IWC and $N_{\mathrm{i}}$ occur slightly above ice saturation at $110 \%$ RHi, while the maximum $D_{\mathrm{i}}$ occur at $130 \%$ RHi. The average IWC and $N_{\mathrm{i}}$ increase 1.5 orders of magnitude from $40 \%$ to $110 \%$ RHi and decrease 0.5 orders of magnitude (i.e., a factor of 3) from $110 \%$ to $130 \%$ RHi. The maximum IWC and $N_{\mathrm{i}}$ do not occur at the highest RHi most likely due to the consumption of water vapor by ice deposition. High $D_{\mathrm{i}}$ values at lower RHi $(\sim 30 \%)$ are likely a result of sedimenting large ice crystals, which has been previously observed by Diao et al. (2013) when investigating the evolutionary phases of cirrus clouds. For $430 \mathrm{~s}$ averaged observations, the peak IWC, $N_{\mathrm{i}}$ and $D_{\mathrm{i}}$ occur at $100 \%, 100 \%$ and $115 \%$ RHi. The maximum IWC and $N_{\mathrm{i}}$ values are nearly the same between 1 and $430 \mathrm{~s}$ averaged observations (i.e., $0.04 \mathrm{~g} \mathrm{~m}^{-3}$ and $10 \mathrm{~L}^{-1}$, respectively) near saturation, while the $430 \mathrm{~s}$ averaged observations show lower minimum IWC and $N_{\mathrm{i}}$ at very low RHi $(<10 \%)$, which are 1.5 orders of magnitude lower than $1 \mathrm{~Hz}$ observations. This feature is due to in-cloud segments being longer around saturation compared with subsaturated conditions as shown in Diao et al. (2013), which means that fewer clear-sky conditions are being included in the $430 \mathrm{~s}$ averages around saturation and therefore show little reduction of the IWC and $N_{\mathrm{i}}$ due to spatial averaging.

In contrast to observations, both CAM6-nudg and CAM6free simulations show bimodal distributions of IWC and $N_{\mathrm{i}}$ with the primary peak at $100 \%$ RHi and the secondary peak at $80 \%$ RHi. The secondary peak at RHi $80 \%$ is likely produced by the $\mathrm{RHi}_{\min }$ parameter reflecting subgrid-scale RHi variance as mentioned above (Gettelman et al., 2010), which was set at the default value ( $80 \% \mathrm{RHi}$ ) for both simulations. The primary peak at $100 \%$ RHi is likely a result of the minimum threshold for heterogeneous ice nucleation being set at $120 \%$ as well as a subgrid variability scaling factor of 1.2 being considered (Wang et al., 2014a). Similar to $430 \mathrm{~s}$ averaged observations, IWC and $N_{\mathrm{i}}$ show steep increase (i.e., 3-4 orders of magnitude) from $40 \%$ to $100 \%$. Increases of average IWC and $N_{\mathrm{i}}$ are seen in the simulations as RHi increases from $120 \%$ to $160 \%$, differing from the decreasing trend seen in the observations. These higher values of IWC and $N_{\mathrm{i}}$ near $160 \%$ are possibly due to RHi reaching the homogeneous nucleation thresholds, where ice nucleation becomes more dependent upon temperature and updraft speed (Liu and Penner, 2005). Note that at this same point as IWC and $N_{\mathrm{i}}$ increase, there is a decrease in $D_{\mathrm{i}}$, which also suggests homogeneous nucleation in the model. For $D_{\mathrm{i}}-\mathrm{RHi}$ correlations, both simulations show similar results to the observations, with the maximum $D_{\mathrm{i}}$ around $130 \%$ RHi and some large ice particles in the subsaturated conditions. The large variability of observed ice microphysical properties is also significantly underestimated in the model for ISS conditions. Standard deviations are $0.5-1$ orders of magnitude lower for
IWC and $N_{\mathrm{i}}$ and a factor of 2 lower for $D_{\mathrm{i}}$ compared with observations.

Comparing the correlations with $\sigma_{w}$ (Fig. 14), the simulations show increasing IWC and $N_{\mathrm{i}}$ with higher $\sigma_{w}$, which agree with observations, although the increases of IWC and $N_{\mathrm{i}}$ are smaller in the simulations than the $430 \mathrm{~s}$ observations. The simulated $D_{\mathrm{i}}$ is relatively constant with increasing $\sigma_{w}$, which differs from the slight positive correlation between $D_{\mathrm{i}}$ and $\sigma_{w}$ in the observations. This slight positive $D_{\mathrm{i}}-\sigma_{w}$ correlation is likely due to the growth of ice particles as cirrus clouds evolve with continuous updrafts that supply excess water vapor above ice saturation, which was previously discussed in a cirrus cloud evolution analysis (Diao et al., 2013). The simulations may overlook this positive correlation for several reasons, such as the lack of temporal resolution to resolve cirrus evolution in the growth phase, the lack of vertical velocity subgrid variabilities (as discussed in Zhou et al., 2016) and a dry bias (i.e., lower RHi) in the model (as discussed in Wu et al., 2017).

Comparing the performance of two types of simulations, both CAM6-nudg and CAM6-free show bimodal distributions for IWC-RHi and $N_{\mathrm{i}}$-RHi correlations, and they both show positive correlations for IWC $-\sigma_{w}$ and $N_{\mathrm{i}}-\sigma_{w}$. This result indicates that the general trends in these correlations are statistically robust and less affected by sampling sizes and geographical locations. For correlations with RHi, the maximum IWC value in CAM6-nudg and CAM6-free is lower than the $430 \mathrm{~s}$ averaged observations by a factors of 25 and 100 , respectively. The maximum $N_{\mathrm{i}}$ value in CAM6-nudg is similar to the $430 \mathrm{~s}$ averaged observations, while that value in CAM6-free is lower by a factor of 3. For correlations with $\sigma_{w}$, there are no significant differences for the maximum IWC between the two simulation types. The maximum $N_{\mathrm{i}}$ value in CAM6-nudg and CAM6-free is higher than the $430 \mathrm{~s}$ averaged observations by factors of 3 and 10, respectively. These results show that CAM6-nudg data, which are collocated with flight tracks, produce IWC and $N_{\mathrm{i}}$ values closer to the $430 \mathrm{~s}$ averaged observations than CAM6-free, possibly due to the variabilities of IWC and $N_{\mathrm{i}}$ in different geographical locations as shown in Fig. 5.

\subsection{Aerosol indirect effects}

The effects of larger and smaller aerosols (i.e., $N_{\mathrm{a}, 500}$ and $\left.N_{\mathrm{a}, 100}\right)$ on ice microphysical properties are further examined for observations and CAM6-nudg data (Figs. 15 and 16). Cloud fraction is calculated in each temperature $-N_{\mathrm{a}}$ bin by normalizing the number of in-cloud samples with the total number of samples in that bin for both observations and simulations. For three cirrus microphysical properties (i.e., IWC, $N_{\mathrm{i}}$ and $D_{\mathrm{i}}$ ), positive correlations are seen in $1 \mathrm{~Hz}$ observations with respect to $N_{\mathrm{a}, 500}$ and $N_{\mathrm{a}, 100}$. In addition, higher $N_{\mathrm{a}, 500}\left(>10 \mathrm{~cm}^{-3}\right)$ and $N_{\mathrm{a}, 100}\left(>100 \mathrm{~cm}^{-3}\right.$ values are associated with significant increases in cloud fraction. At -70 to $-60^{\circ} \mathrm{C}$, higher IWC, $N_{\mathrm{i}}$ and cloud fraction are seen when 

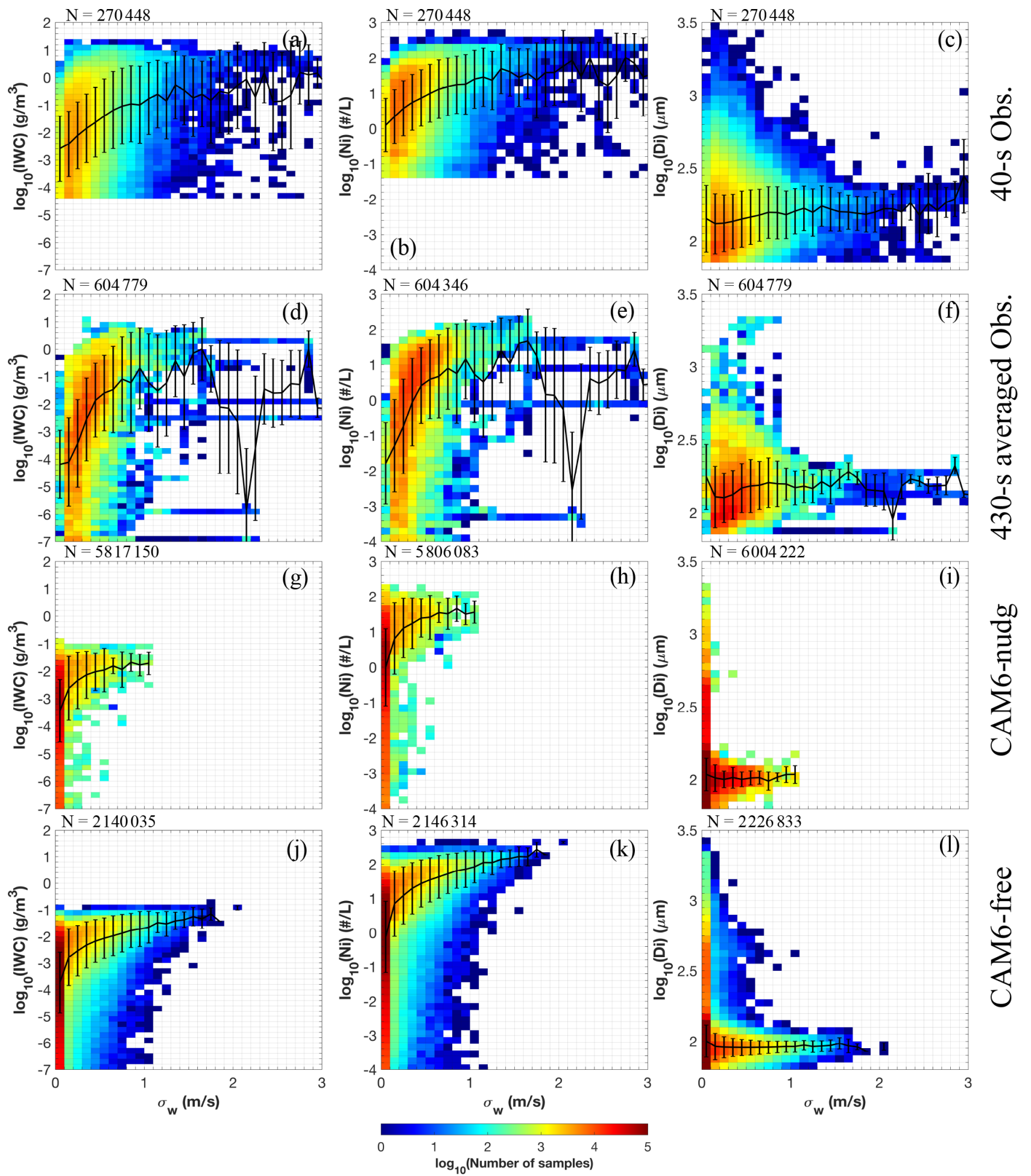

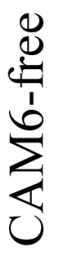

Figure 14. Similar to Fig. 13 but for correlations with $\sigma_{w}$. Note that $\sigma_{w}$ values of observations are calculated for panels (a-c) every $40 \mathrm{~s}$ and (d-f) every 430 s using the $1 \mathrm{~Hz}$ observations. 


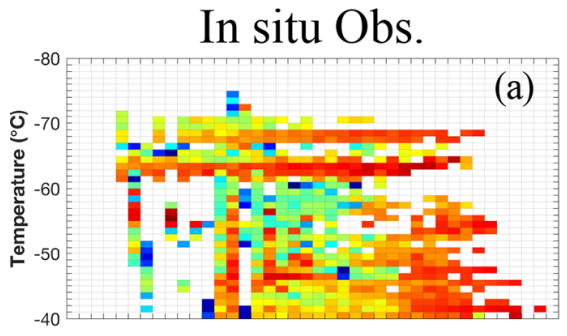

430-s averaged Obs.
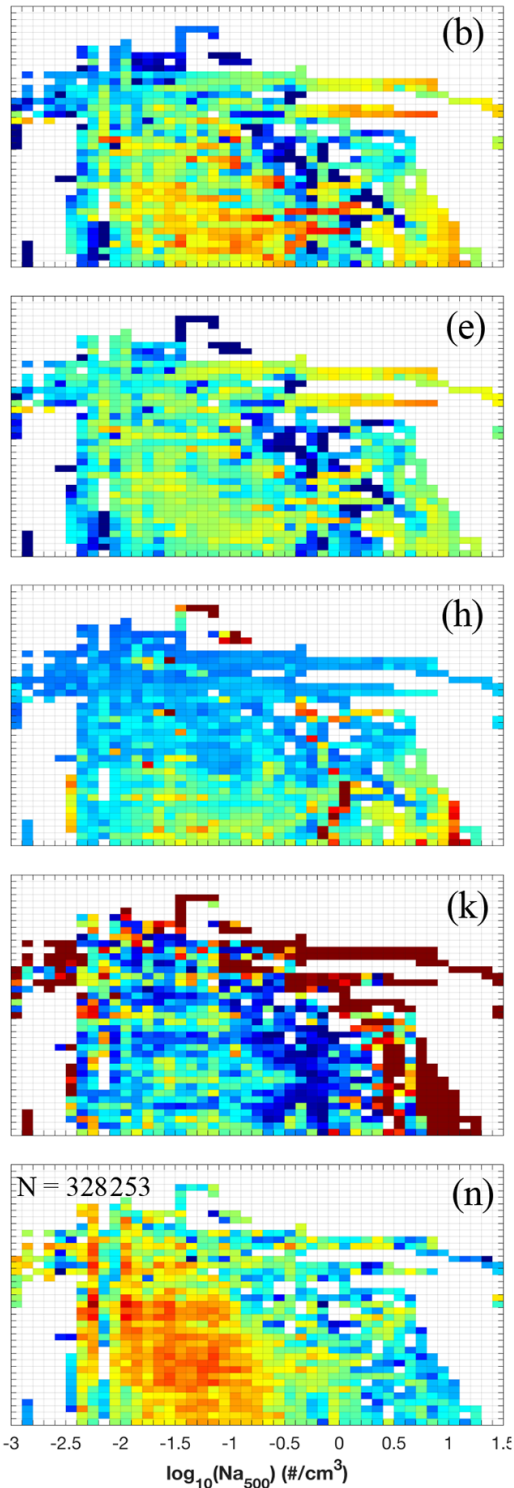

CAM6-nudg

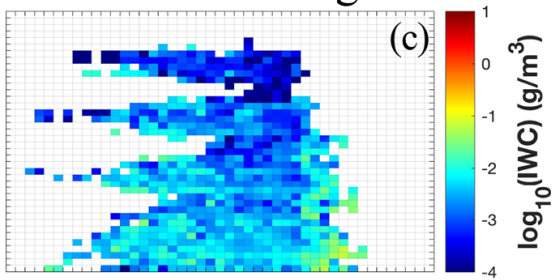

(f)
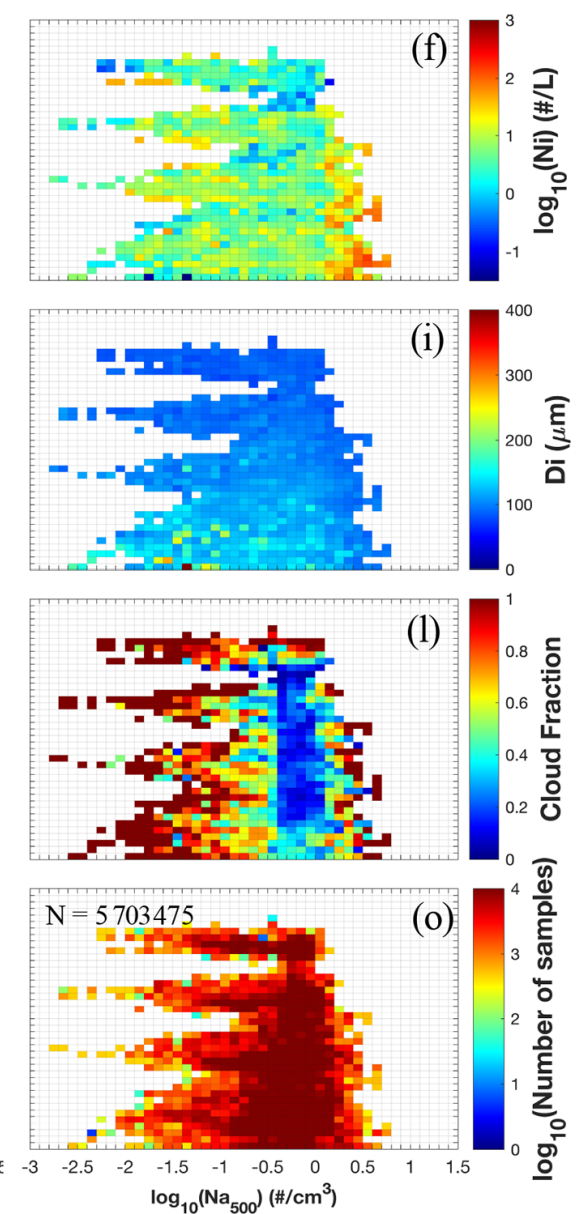

Figure 15. Aerosol indirect effects from logarithmic-scale $N_{\mathrm{a}, 500}$ on $(\mathbf{a}-\mathbf{c})$ IWC, $(\mathbf{d}-\mathbf{f}) N_{\mathrm{i}},(\mathbf{g}-\mathbf{i}) D_{\mathrm{i}}$ and (j-l) cloud fraction, compared among $1 \mathrm{~Hz}$ observations (left column), $430 \mathrm{~s}$ averaged observations (middle column) and CAM6-nudg data (right column). Number of samples of each bin is shown in the bottom row $(\mathbf{m}-\mathbf{o})$. Cloud fraction is calculated as the number of in-cloud samples over the total number of samples for a given temperature and $N_{\mathrm{a}}$ bin.

$N_{\mathrm{a}, 500}$ is observed, with positive correlations of IWC and $N_{\mathrm{i}}$ with respect to $N_{\mathrm{a}, 500}$. This finding indicates that larger aerosols provide an effective pathway of ice particle formation for colder conditions. The higher IWC and $N_{\mathrm{i}}$ are only shown in much higher $N_{\mathrm{a}, 100}\left(>100 \mathrm{~cm}^{-3}\right)$ between -70 and $-60^{\circ} \mathrm{C}$, demonstrating that larger aerosols facilitate ice formation more effectively than smaller aerosols at this temperature range, possibly due to the activation of larger aerosols as INPs for heterogeneous nucleation. Compared with $1 \mathrm{~Hz}$ observations, $430 \mathrm{~s}$ averaged observations show weaker correlations of IWC, $N_{\mathrm{i}}$ and $D_{\mathrm{i}}$ with respect to $N_{\mathrm{a}}$.
However, they do still show higher IWC and $N_{\mathrm{i}}$ between -70 and $-40^{\circ} \mathrm{C}$ associated with higher $N_{\mathrm{a}}$ (i.e., $N_{\mathrm{a}, 500}>1 \mathrm{~cm}^{-3}$ and $N_{\mathrm{a}, 100}>30 \mathrm{~cm}^{-3}$ ).

The CAM6-nudg simulation shows increasing average IWC, average $N_{\mathrm{i}}$ and cloud fraction with increasing $N_{\mathrm{a}, 500}$, consistent with the observations. But at temperatures below $-60{ }^{\circ} \mathrm{C}$, simulated IWC and $N_{\mathrm{i}}$ do not show a sudden increase with higher $N_{\mathrm{a}, 500}$ as shown in the observations. The simulated $D_{\mathrm{i}}$ slightly decreases with increasing $N_{\mathrm{a}, 500}$, differing from the increasing trend seen in observations. For aerosol indirect effect analysis based on $N_{\mathrm{a}, 100}$, the com- 

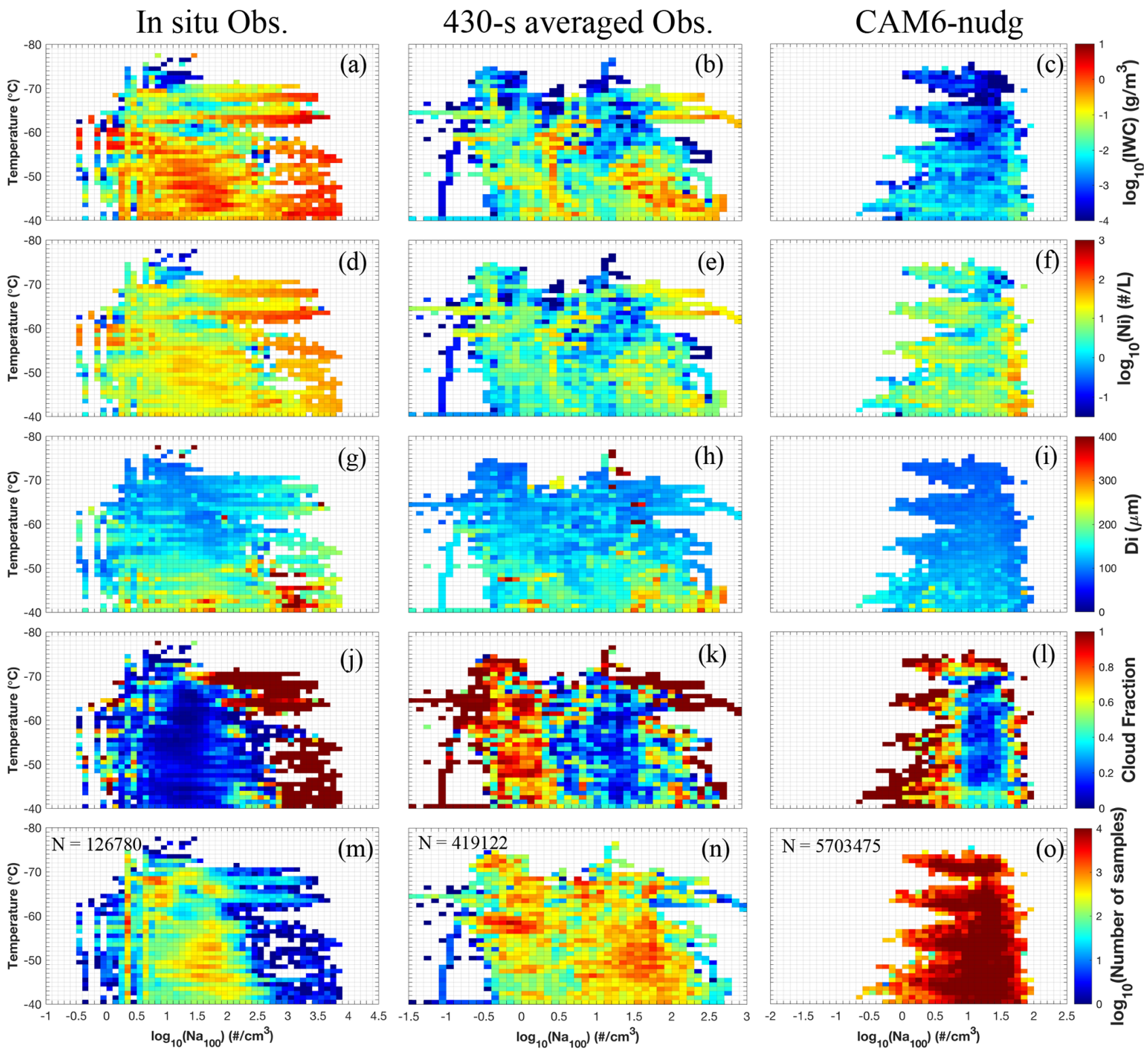

Figure 16. Similar to Fig. 15 but examined for $\log _{10}\left(N_{\mathrm{a}, 100}\right)$.

parison results are similar to $N_{\mathrm{a}, 500}$; that is, the CAM6nudg simulation is able to represent positive correlations of IWC, $N_{\mathrm{i}}$ and cloud fraction with respect to $N_{\mathrm{a}, 100}$. However, the CAM6-nudg simulation shows smaller (larger) increase of IWC $\left(N_{\mathrm{i}}\right)$ at very high $N_{\mathrm{a}}$ (i.e., $N_{\mathrm{a}, 500}>1.6 \mathrm{~cm}^{-3}$ and $\left.N_{\mathrm{a}, 100}>30 \mathrm{~cm}^{-3}\right)$ compared with the $430 \mathrm{~s}$ averaged observations. The model also misses positive correlations between $D_{\mathrm{i}}$ and $N_{\mathrm{a}}$ seen in both $1 \mathrm{~Hz}$ and $430 \mathrm{~s}$ averaged observations.

\section{Discussion and conclusions}

In this study, we investigate the statistical distributions of cirrus cloud microphysical properties (i.e., IWC, $N_{\mathrm{i}}$ and $D_{\mathrm{i}}$ ) as well as several key controlling factors (i.e., temperature, $\mathrm{RHi}, \sigma_{w}$ and $N_{\mathrm{a}}$ ) using a comprehensive in situ observational dataset and GCM simulations. Regional variations of cirrus cloud microphysical properties are examined for six latitudinal regions in two hemispheres. Two types of CAM6 simulations are evaluated, i.e., nudged and free-running simulations.

Regarding the regional variations in $1 \mathrm{~Hz}$ observations, the highest and lowest IWC values were observed in NH midlatitudes and SH midlatitudes, respectively, while the polar regions show the lowest $N_{\mathrm{i}}$ and highest $D_{\mathrm{i}}$ at warmer conditions (i.e., -55 to $-40^{\circ} \mathrm{C}$ ) (Fig. 5). The hemispheric differences between $\mathrm{NH}$ and $\mathrm{SH}$ midlatitudes indicate a possible role of anthropogenic aerosols and/or land-sea contrast 
in controlling ice microphysical properties. Thermodynamic and dynamic conditions can also affect nucleation mechanisms. For example, the tropical regions show the highest IWC and $N_{\mathrm{i}}$ at temperatures below $-55^{\circ} \mathrm{C}$ possibly due to convection anvils with the droplet freezing from down below or homogeneous nucleation in gravity waves generated by convection. This feature is corroborated by the fact that tropical regions show the highest RHi values for both clear-sky and in-cloud conditions (Fig. 6), while the midlatitude and polar regions show fewer samples exceeding the homogeneous nucleation threshold. The higher RHi values in tropics are likely contributed by higher updrafts (indicated by higher $\sigma_{w}$ in Fig. 9). These results demonstrate the important roles of these controlling factors on cirrus clouds at different latitudinal and temperature ranges.

Evaluating the model simulations of cirrus microphysical properties, different model performance results are seen in different regions. For example, simulations underestimated the IWC in NH (Fig. 5), possibly due to model dry bias to form ice clouds (as discussed in Wu et al., 2017) and/or smaller aerosol indirect effects on IWC in the simulations (Figs. 15 and 16). Differences in the particle size distribution, such as lower number density of larger particles $(>1000 \mu \mathrm{m})$ in the simulation (Fig. 4a), may also contribute to the underestimation of IWC by the simulation. All the comparison results on IWC, $N_{\mathrm{i}}$ and $D_{\mathrm{i}}$ are only applicable to the size range being evaluated $(\geq 62.5 \mu \mathrm{m})$. For RHi distributions, both simulations represent a similar peak position at ice saturation for in-cloud RHi PDFs compared with observations but CAM6-nudg underestimates the frequency and magnitude of ISS for clear-sky condition. For $\sigma_{w}$ distributions, simulations represent similar regional variations of $\sigma_{w}$ compared with observations, with $\sigma_{w}$ decreasing from lower to higher latitudes. The model performs well for representing the effects of RHi and $\sigma_{w}$ on ice microphysical properties, specifically for showing the maximum IWC and $N_{\mathrm{i}}$ at $100 \%$ RHi and the positive correlations with $\sigma_{w}$. Some differences include the simulated average IWC and $N_{\mathrm{i}}$ showing a secondary peak position at $80 \% \mathrm{RHi}$, likely due to the minimum RHi threshold used in the model parameterization. Both simulation types show similar correlation trends of ice microphysical properties with respect to RHi and $\sigma_{w}$. CAM6-nudg performs better for representing IWC and $N_{\mathrm{i}}$ magnitudes than CAM6-free, possibly due to better collocation between CAM6-nudg and observations.

For aerosol indirect effects, the simulations underestimate IWC, $N_{\mathrm{i}}, D_{\mathrm{i}}$ as well as cloud fraction at colder conditions $\left(<-60^{\circ} \mathrm{C}\right)$ when larger aerosols exist, indicating that the effectiveness of larger aerosols is underestimated at the colder conditions. The observations also show higher $D_{\mathrm{i}}$ than simulations by a factor of 3-4 at warmer temperatures ( -50 to $-40^{\circ} \mathrm{C}$ ), indicating misrepresentation of ice particle growth and/or sedimentation in the simulations. In addition, the IWC, $N_{\mathrm{i}}$ and $D_{\mathrm{i}}$ in $430 \mathrm{~s}$ averaged observations show an increase at higher $N_{\mathrm{a}, 500}\left(>1 \mathrm{~cm}^{-3}\right)$ and $N_{\mathrm{a}, 100}\left(>30 \mathrm{~cm}^{-3}\right)$, while simulations only show a significant increase of $N_{\mathrm{i}}$. This result indicates that aerosol indirect effects may be underestimated especially for higher $N_{\mathrm{a}}$ values. It is possible that small ice crystals $<62.5 \mu \mathrm{m}$ may have formed under high $N_{\mathrm{a}}$ but are excluded due to the size constraint. Additionally, because INP activation is highly dependent upon temperature, we acknowledge the limitation of using $N_{\mathrm{a}, 500}$ to indicate INP concentrations. The assumption of ice mass and dimension relationship from Brown and Francis (1995) may also lead to uncertainties due to various ice habits. These caveats call for more investigation of small ice measurements, INP measurements at temperature $\leq-40^{\circ} \mathrm{C}$ and measurements of various ice habits.

Overall, the global-scale observational dataset used in this study provides statistically robust distributions of cirrus cloud microphysical properties, which can be used to evaluate the effects of thermodynamics, dynamics and aerosols on cirrus clouds in a global climate model. Extending from previous studies that investigated climate model sensitivity to individual cirrus cloud controlling factors, i.e., $w$ (Shi and Liu, 2016), RHi (D'Alessandro et al., 2019), water vapor (Wu et al., 2017) and aerosols (Wang et al., 2014a), this study provides an analysis of all factors. In addition, further attention was given towards evaluating these factors in the simulations based on geographical locations. For both observations and simulations, higher ice supersaturations and stronger vertical motions are shown in tropical and midlatitude regions, which possibly lead to increased homogeneous nucleation and convection-generated cirrus, consistent with higher IWC and $N_{\mathrm{i}}$ and lower $D_{\mathrm{i}}$ in these regions compared with polar regions. In addition, underestimating aerosol indirect effects in the simulations likely contributes to the underestimation of IWC in the NH. Even though small ice particles $(<62.5 \mu \mathrm{m})$ are excluded in this study, correlations between ice microphysical properties and these key controlling factors are still clearly seen in the observation dataset. In addition, using two methods that compare observations on the horizontal scales of $230 \mathrm{~m}$ and $100 \mathrm{~km}$ with simulations, both methods show similar signs for model biases of IWC, $N_{\mathrm{i}}$ and $D_{\mathrm{i}}$, while smaller model biases are seen when comparing against the coarser resolution observations. This study underscores the importance of correctly representing the thermodynamic, dynamic and aerosol conditions in climate models at various regions, as well as accurately simulating their correlations with ice microphysical properties. Failing to do so may result in biases of cirrus cloud microphysical properties depending on different regions and temperatures, leading to biases in cirrus cloud radiative effects on a global scale.

Code availability. The source code and namelist of the CAM6 model version used in this work are archived on the NCAR Cheyenne campaign storage system under /glade/campaign/univ/usjs0006/. Access will be granted by the authors on request. 
Data availability. Observations from the seven NSF flight campaigns are accessible at https://data.eol.ucar.edu/ (last access: 11 December 2020): https://doi.org/10.5065/D6Z31X06 (UCAR/NCAR - Earth Observing Laboratory, 2009), https://doi.org/10.5065/D6BC3WKB (UCAR/NCAR - Earth Observing Laboratory, 2018a), https://doi.org/10.5065/D6TX3CK0 (UCAR/NCAR - Earth Observing Laboratory, 2018b), https://doi.org/10.5065/D65T3HWR (UCAR/NCAR - Earth Observing Laboratory, 2018c), https://doi.org/10.5065/D6NZ85Z4 (UCAR/NCAR - Earth Observing Laboratory, 2019a), https://doi.org/10.5065/D6JW8C64 (UCAR/NCAR - Earth Observing Laboratory, 2019b), https://doi.org/10.5065/D6QF8R6R (UCAR/NCAR - Earth Observing Laboratory, 2019c), https://doi.org/10.5065/D6V40SK6 (UCAR/NCAR - Earth Observing Laboratory, 2019d), https://doi.org/10.5065/D6CZ35HX (UCAR/NCAR - Earth Observing Laboratory, 2019e), https://doi.org/10.5065/D61R6NV5 (UCAR/NCAR - Earth Observing Laboratory, 2019f), https://doi.org/10.5065/D6668BHR (UCAR/NCAR - Earth Observing Laboratory, 2019g).

Supplement. The supplement related to this article is available online at: https://doi.org/10.5194/acp-21-1835-2021-supplement.

Author contributions. RP and MD contributed to the development of the ideas, conducted quality control of aircraft-based observations and wrote the majority of the manuscript. RP contributed to all model simulations and the subsequent data analysis. XL and SC provided expertise on the setup of CAM6 model simulations and provided input for the analysis of simulation data.

Competing interests. The authors declare that they have no conflict of interest.

Acknowledgements. Ryan Patnaude, Minghui Diao, Xiaohong Liu and Suqian Chu acknowledge funding support from US National Science Foundation (see financial support below). Ryan Patnaude also acknowledges support from the San Jose State University Walker Fellowship. For funding support during the summers of 2016 and 2018, Minghui Diao acknowledges the NCAR Advanced Study Program (ASP) Faculty Fellowship. We would like to acknowledge the NCAR/Earth Observation Laboratory flight teams from the seven flight campaigns: START08, HIPPO, PREDICT, DC3, CONTRAST, TORERO and ORCAS. For in situ observations of water vapor by the VCSEL hygrometer, field support, calibration and QA/QC were conducted by Minghui Diao, Joshua DiGangi, Mark Zondlo and Stuart Beaton. Additional appreciation is given to Jorgen Jensen, Chris Webster and Christina McCluskey for helpful discussions.

Financial support. This research has been supported by the National Science Foundation, Directorate for Geosciences (grant nos. AGS-1642291, OPP-1744965 and AGS-1642289/2001903).
Review statement. This paper was edited by Martina Krämer and reviewed by two anonymous referees.

\section{References}

Barth, M. C., Cantrell, C. A., Brune, W. H., Rutledge, S. A., Crawford, J. H., Huntrieser, H., Carey, L. D., MacGorman, D., Weisman, M., Pickering, K. E., Bruning, E., Anderson, B., Apel, E., Biggerstaff, M., Campos, T., Campuzano-Jost, P., Cohen, R., Crounse, J., Day, D. A., Diskin, G., Flocke, F., Fried, A., Garland, C., Heikes, B., Honomichl, S., Hornbrook, R., Gregory Huey, L., Jimenez, J. L., Lang, T., Lichtenstern, M., Mikoviny, T., Nault, B., O’Sullivan, D., Pan, L. L., Peischl, J., Pollack, I., Richter, D., Riemer, D., Ryerson, T., Schlager, H., St. Clair, J., Walega, J., Weibring, P., Weinheimer, A., Wennberg, P., Wisthaler, A., Wooldridge, P. J., and Ziegler, C.: The Deep Convective Clouds and Chemistry (DC3) field campaign, B. Am. Meteorol. Soc., 96, 1281-1310, https://doi.org/10.1175/BAMSD-13-00290.1, 2015.

Bogenschutz, P. A., Gettelman, A., Morrison, H., Larson, V. E., Craig, C., and Schanen, D. P.: Higher-order turbulence closure and its impact on climate simulations in the community atmosphere model, J. Climate, 26, 9655-9676, https://doi.org/10.1175/JCLI-D-13-00075.1, 2013.

Boucher, O., Randall, D., Artaxo, P., Bretherton, C., Feingold, G., Forster, P., Kerminen, V.-M., Kondo, Y., Liao, H., Lohmann, U., Rasch, P., Satheesh, S. K., Sherwood, S. C., Stevens, B., and Zhang, X.-Y.: Clouds and aerosols, Clim. Chang. 2013 Phys. Sci. Basis Work. Gr. I Contrib. to Fifth Assess. Rep. Intergov. Panel Clim. Chang., 9781107057, 571-658, https://doi.org/10.1017/CBO9781107415324.016, 2013.

Brown, P. R. A. and Francis, P. N.: Improved Measurements of the Ice Water Content in Cirrus Using a Total-Water Probe, J. Atmos. Ocean. Tech., 12, 410-414, https://doi.org/10.1175/15200426(1995)012<0410:IMOTIW>2.0.CO;2, 1995.

Chylek, P., Dubey, M. K., Lohmann, U., Ramanathan, V., Kaufman, Y. J., Lesins, G., Hudson, J., Altmann, G., and Olsen, S.: Aerosol indirect effect over the Indian Ocean, Geophys. Res. Lett., 33, L06806, https://doi.org/10.1029/2005GL025397, 2006.

Cziczo, D. J. and Froyd, K. D.: Sampling the composition of cirrus ice residuals, Atmos. Res., 142, 15-31, https://doi.org/10.1016/j.atmosres.2013.06.012, 2014.

Cziczo, D. J., Froyd, K. D., Hoose, C., Jensen, E. J., Diao, M., Zondlo, M. A., Smith, J. B., Twohy, C. H., and Murphy, D. M.: Clarifying the dominant sources and mechanisms of cirrus cloud formation, Science, 340, 1320-1324, https://doi.org/10.1126/science.1234145, 2013.

D’Alessandro, J. J., Diao, M., Wu, C., Liu, X., Chen, M., Morrison, H., Eidhammer, T., Jensen, J. B., Bansemer, A., Zondlo, M. A., and DiGangi, J. P.: Dynamical conditions of ice supersaturation and ice nucleation in convective systems: A comparative analysis between in situ aircraft observations and WRF simulations, J. Geophys. Res., 122, 2844-2866, https://doi.org/10.1002/2016JD025994, 2017.

D’Alessandro, J. J., Diao, M., Wu, C., Liu, X., Jensen, J. B., and Stephens, B. B.: Cloud phase and relative humidity distributions over the Southern Ocean in austral summer based on in situ ob- 
servations and CAM5 simulations, J. Climate, 32, 2781-2805, https://doi.org/10.1175/JCLI-D-18-0232.1, 2019.

DeMott, P. J., Prenni, A. J., Liu, X., Kreidenweis, S. M., Petters, M. D., Twohy, C. H., Richardson, M. S., Eidhammer, T., and Rogers, D. C.: Predicting global atmospheric ice nuclei distributions and their impacts on climate, P. Natl. Acad. Sci. USA, 107, 1121711222, https://doi.org/10.1073/pnas.0910818107, 2010.

Diao, M., Zondlo, M. A., Heymsfield, A. J., Beaton, S. P., and Rogers, D. C.: Evolution of ice crystal regions on the microscale based on in situ observations, Geophys. Res. Lett., 40, 34733478, https://doi.org/10.1002/grl.50665, 2013.

Diao, M., Zondlo, M. A., Heymsfield, A. J., Avallone, L. M., Paige, M. E., Beaton, S. P., Campos, T., and Rogers, D. C.: Cloudscale ice-supersaturated regions spatially correlate with high water vapor heterogeneities, Atmos. Chem. Phys., 14, 2639-2656, https://doi.org/10.5194/acp-14-2639-2014, 2014a.

Diao, M., Zondlo, M. A., Heymsfield, A. J., and Beaton, S. P.: Hemispheric comparison of cirrus cloud evolution using in situ measurements in HIAPER Pole-to-Pole Observations, Geophys. Res. Lett., 41, 1-8, https://doi.org/10.1002/2014GL059873, 2014b.

Diao, M., Jensen, J. B., Pan, L. L., Homeyer, C. R., Honomichl, S., Bresch, J. F., and Bansemer, A.: Distributions of ice supersaturation and ice crystals from airborne observations in relation to upper tropospheric dynamical boundaries, J. Geophys. Res., 120, 5101-5121, https://doi.org/10.1002/2015JD023139, 2015.

Diao, M., Bryan, G. H., Morrison, H., and Jensen, J. B.: Ice nucleation parameterization and relative humidity distribution in idealized squall-line simulations, J. Atmos. Sci., 74, 2761-2787, https://doi.org/10.1175/JAS-D-16-0356.1, 2017.

Eidhammer, T., Morrison, H., Bansemer, A., Gettelman, A., and Heymsfield, A. J.: Comparison of ice cloud properties simulated by the Community Atmosphere Model (CAM5) with in-situ observations, Atmos. Chem. Phys., 14, 10103-10118, https://doi.org/10.5194/acp-14-10103-2014, 2014.

Eidhammer, T., Morrison, H., Mitchell, D., Gettelman, A., and Erfani, E.: Improvements in global climate model microphysics using a consistent representation of ice particle properties, J. Climate, 30, 609-629, https://doi.org/10.1175/JCLI-D-16-0050.1, 2017.

Gelaro, R., McCarty, W., Suárez, M. J., Todling, R., Molod, A., Takacs, L., Randles, C. A., Darmenov, A., Bosilovich, M. G., Reichle, R., Wargan, K., Coy, L., Cullather, R., Draper, C., Akella, S., Buchard, V., Conaty, A., da Silva, A. M., Gu, W., Kim, G. K., Koster, R., Lucchesi, R., Merkova, D., Nielsen, J. E., Partyka, G., Pawson, S., Putman, W., Rienecker, M., Schubert, S. D., Sienkiewicz, M., and Zhao, B.: The modern-era retrospective analysis for research and applications, version 2 (MERRA-2), J. Climate, 30, 5419-5454, https://doi.org/10.1175/JCLI-D-160758.1, 2017.

Gettelman, A. and Morrison, H.: Advanced two-moment bulk microphysics for global models. Part I: Off-line tests and comparison with other schemes, J. Climate, 28, 1268-1287, https://doi.org/10.1175/JCLI-D-14-00102.1, 2015.

Gettelman, A., Liu, X., Ghan, S. J., Morrison, H., Park, S., Conley, A. J., Klein, S. A., Boyle, J., Mitchell, D. L., and Li, J. L. F.: Global simulations of ice nucleation and ice supersaturation with an improved cloud scheme in the Commu- nity Atmosphere Model, J. Geophys. Res.-Atmos., 115, 1-19, https://doi.org/10.1029/2009JD013797, 2010.

Gettelman, A., Bardeen, C. G., McCluskey, C. S., Järvinen, E., Stith, J., Bretherton, C., McFarquhar, G., Twohy, C., D'Alessandro, J., and Wu, W.: Simulating Observations of Southern Ocean Clouds and Implications for Climate, J. Geophys. Res.-Atmos., 125, e2020JD032619, https://doi.org/10.1029/2020JD032619, 2020.

Golaz, J. C., Larson, V. E., and Cotton, W. R.: A PDF-Based Model for Boundary Layer Clouds. Part I: Method and Model Description, J. Atmos. Sci., 59, 3540-3551, 2002.

Heymsfield, A. J.: Precipitation Development in Stratiform Ice Clouds: A Microphysical and Dynamical Study, J. Atmos. Sci., 367-381, 1977.

Heymsfield, A. J., Winker, D., and van Zadelhoff, G. J.: Extinction-ice water content-effective radius algorithms for CALIPSO, Geophys. Res. Lett., 32, 1-4, https://doi.org/10.1029/2005GL022742, 2005.

Heymsfield, A. J., Krämer, M., Wood, N. B., Gettelman, A., Field, P. R., and Liu, G.: Dependence of the Ice Water Content and Snowfall Rate on Temperature, Globally: Comparison of in Situ Observations, Satellite Active Remote Sensing Retrievals, and Global Climate Model Simulations, J. Appl. Meteorol. Climatol., 56, 189-215, https://doi.org/10.1175/JAMC-D-16-0230.1, 2017.

Hoose, C., Kristjánsson, J. E., Chen, J. P., and Hazra, A.: A classical-theory-based parameterization of heterogeneous ice nucleation by mineral dust, soot, and biological particles in a global climate model, J. Atmos. Sci., 67, 2483-2503, https://doi.org/10.1175/2010JAS3425.1, 2010.

Jensen, E. J., Toon, O. B., Vay, S. A., Ovarlez, J., May, R., Bui, T. P., Twohy, C. H., Gandrud, B. W., Pueschel, R. F., and Schumann, U.: Prevalence of ice-supersaturated regions in the upper troposphere: Implications for optically thin ice cloud formation, J. Geophys. Res.-Atmos., 106, 17253-17266, https://doi.org/10.1029/2000JD900526, 2001.

Kanitz, T., Seifert, P., Ansmann, A., Engelmann, R., Althausen, D., Casiccia, C., and Rohwer, E. G.: Contrasting the impact of aerosols at northern and southern midlatitudes on heterogeneous ice formation, Geophys. Res. Lett., 38, 1-5, https://doi.org/10.1029/2011GL048532, 2011.

Kärcher, B. and Lohmann, U.: A parameterization of cirrus cloud formation: Homogeneous freezing of supercooled aerosols, J. Geophys. Res., 107, D2, https://doi.org/10.1029/2001JD000470, 2002.

Kärcher, B. and Lohmann, U.: A parameterization of cirrus cloud formation: Heterogeneous freezing, J. Geophys. Res., 107, 4402, https://doi.org/10.1029/2002JD003220, 2003.

Kärcher, B., Hendricks, J., and Lohmann, U.: Physically based parameterization of cirrus cloud formation for use in global atmospheric models, J. Geophys. Res.-Atmos., 111, D01205, https://doi.org/10.1029/2005JD006219, 2006.

Koop, T., Luo, B., Tsias, A., and Peter, T.: Water activity as the determinant for homogeneous ice nucleation in aqueous solutions, Nature, 406, 611-614, https://doi.org/10.1038/35020537, 2000.

Kooperman, G. J., Pritchard, M. S., Ghan, S. J., Wang, M., Somerville, R. C. J., and Russell, L. M.: Constraining the influence of natural variability to improve estimates of global aerosol indirect effects in a nudged version of the Commu- 
nity Atmosphere Model 5, J. Geophys. Res.-Atmos., 117, 1-16, https://doi.org/10.1029/2012JD018588, 2012.

Krämer, M., Schiller, C., Afchine, A., Bauer, R., Gensch, I., Mangold, A., Schlicht, S., Spelten, N., Sitnikov, N., Borrmann, S., de Reus, M., and Spichtinger, P.: Ice supersaturations and cirrus cloud crystal numbers, Atmos. Chem. Phys., 9, 3505-3522, https://doi.org/10.5194/acp-9-3505-2009, 2009.

Krämer, M., Rolf, C., Luebke, A., Afchine, A., Spelten, N., Costa, A., Meyer, J., Zöger, M., Smith, J., Herman, R. L., Buchholz, B., Ebert, V., Baumgardner, D., Borrmann, S., Klingebiel, M., and Avallone, L.: A microphysics guide to cirrus clouds - Part 1: Cirrus types, Atmos. Chem. Phys., 16, 3463-3483, https://doi.org/10.5194/acp-16-3463-2016, 2016.

Krämer, M., Rolf, C., Spelten, N., Afchine, A., Fahey, D., Jensen, E., Khaykin, S., Kuhn, T., Lawson, P., Lykov, A., Pan, L. L., Riese, M., Rollins, A., Stroh, F., Thornberry, T., Wolf, V., Woods, S., Spichtinger, P., Quaas, J., and Sourdeval, O.: A microphysics guide to cirrus - Part 2: Climatologies of clouds and humidity from observations, Atmos. Chem. Phys., 20, 12569-12608, https://doi.org/10.5194/acp-20-12569-2020, 2020.

Kuebbeler, M., Lohmann, U., Hendricks, J., and Kärcher, B.: Dust ice nuclei effects on cirrus clouds, Atmos. Chem. Phys., 14, 3027-3046, https://doi.org/10.5194/acp-14-3027-2014, 2014.

Lin, S. J.: A "vertically Lagrangian" finite-volume dynamical core for global models, Mon. Weather Rev., 132, 2293-2307, https://doi.org/10.1175/15200493(2004)132<2293:AVLFDC>2.0.CO;2, 2004.

Liu, X. and Penner, J. E.: Ice nucleation parameterization for global models, Meteorol. Zeitschrift, 14, 499-514, https://doi.org/10.1127/0941-2948/2005/0059, 2005.

Liu, X., Penner, J. E., Ghan, S. J., and Wang, M.: Inclusion of ice microphysics in the NCAR Community Atmospheric Model version 3 (CAM3), J. Climate, 20, 4526-4547, https://doi.org/10.1175/JCLI4264.1, 2007.

Liu, X., Shi, X., Zhang, K., Jensen, E. J., Gettelman, A., Barahona, D., Nenes, A., and Lawson, P.: Sensitivity studies of dust ice nuclei effect on cirrus clouds with the Community Atmosphere Model CAM5, Atmos. Chem. Phys., 12, 12061-12079, https://doi.org/10.5194/acp-12-12061-2012, 2012.

Liu, X., Ma, P.-L., Wang, H., Tilmes, S., Singh, B., Easter, R. C., Ghan, S. J., and Rasch, P. J.: Description and evaluation of a new four-mode version of the Modal Aerosol Module (MAM4) within version 5.3 of the Community Atmosphere Model, Geosci. Model Dev., 9, 505-522, https://doi.org/10.5194/gmd-9505-2016, 2016.

Luebke, A. E., Avallone, L. M., Schiller, C., Meyer, J., Rolf, C., and Krämer, M.: Ice water content of Arctic, midlatitude, and tropical cirrus - Part 2: Extension of the database and new statistical analysis, Atmos. Chem. Phys., 13, 6447-6459, https://doi.org/10.5194/acp-13-6447-2013, 2013.

Luebke, A. E., Afchine, A., Costa, A., Grooß, J.-U., Meyer, J., Rolf, C., Spelten, N., Avallone, L. M., Baumgardner, D., and Krämer, M.: The origin of midlatitude ice clouds and the resulting influence on their microphysical properties, Atmos. Chem. Phys., 16, 5793-5809, https://doi.org/10.5194/acp-16-5793-2016, 2016.

Mace, G. G. and Wrenn, F. J.: Evaluation of the hydrometeor layers in the East and West Pacific within ISCCP cloud-top pressureoptical depth bins using merged CloudSat and CALIPSO data,
J. Climate, 26, 9429-9444, https://doi.org/10.1175/JCLI-D-1200207.1, 2013.

Mcfarquhar, G. M. and Heymsfield, A. J.: Parameterization of tropical cirrus ice crystal size distributions and implications for radiative transfer: Results from CEPEX, J. Atmos. Sci., 54, 2187-2200, https://doi.org/10.1175/15200469(1997)054<2187:POTCIC>2.0.CO;2, 1997.

Minikin, A., Petzold, A., Ström, J., Krejci, R., Seifert, M., van Velthoven, P., Schlager, H., and Schumann, U.: Aircraft observations of the upper tropospheric fine particle aerosol in the Northern and Southern Hemispheres at midlatitudes, Geophys. Res Lett., 30, 1503, https://doi.org/10.1029/2002GL016458, 2003.

Mitchell, D. L., Garnier, A., Pelon, J., and Erfani, E.: CALIPSO (IIR-CALIOP) retrievals of cirrus cloud iceparticle concentrations, Atmos. Chem. Phys., 18, 17325-17354, https://doi.org/10.5194/acp-18-17325-2018, 2018.

Montgomery, M. T., Davis, C., Dunkerton, T., Wang, Z., Velden, C., Torn, R., Majumdar, S. J., Zhang, F., Smith, R. K., Bosart, L., Bell, M. M., Haase, J. S., Heymsfield, A., Jensen, J., Campos, T., and Boothe, M. A.: The pre-depression investigation of cloud-systems in the tropics (PREDICT) experiment: Scientific basis, new analysis tools, and some first results, B. Am. Meteorol. Soc., 93, 153-172, https://doi.org/10.1175/BAMS-D-1100046.1, 2012.

Morrison, H. and Gettelman, A.: A new two-moment bulk stratiform cloud microphysics scheme in the community atmosphere model, version 3 (CAM3). Part I: Description and numerical tests, J. Climate, 21, 3642-3659, https://doi.org/10.1175/2008JCLI2105.1, 2008.

Muhlbauer, A., Ackerman, T. P., Comstock, J. M., Diskin, G. S., Evans, S. M., Lawson, R. P., and Marchand, R. T.: Impact of large-scale dynamics on the microphysical properties of midlatitude cirrus, J. Geophys. Res., 119, 3976-3996, https://doi.org/10.1002/2013JD020035, 2014a.

Muhlbauer, A., Kalesse, H., and Kollias, P.: Vertical velocities and turbulence in midlatitude anvil cirrus: A comparison between in situ aircraft measurements and ground-based Doppler cloud radar retrievals, Geophys. Res. Lett., 41, 7814-7821, https://doi.org/10.1002/2014GL062279, 2014b.

Murphy, D. M. and Koop, T.: Review of the vapour pressures of ice and supercooled water for atmospheric applications, Q. J. Roy. Meteor. Soc., 131, 1539-1565, https://doi.org/10.1256/qj.04.94, 2005.

Pan, L. L., Bowman, K. P., Atlas, E. L., Wofsy, S. C., Zhang, F., Bresch, J. F., Ridley, B. A., Pittman, J. V., Homeyer, C. R., Romashkin, P., and Cooper, W. A.: The stratosphere-troposphere analyses of regional transport 2008 experiment, B. Am. Meteorol. Soc., 91, 327-342, https://doi.org/10.1175/2009BAMS2865.1, 2010.

Pan, L. L., Atlas, E. L., Salawitch, R. J., Honomichl, S. B., Bresch, J. F., Randel, W. J., Apel, E. C., Hornbrook, R. S., Weinheimer, A. J., Anderson, D. C., Andrews, S. J., Baidar, S., Beaton, S. P., Campos, T. L., Carpenter, L. J., Chen, D., Dix, B., Donets, V., Hall, S. R., Hanisco, T. F., Homeyer, C. R., Huey, L. G., Jensen, J. B., Kaser, L., Kinnison, D. E., Koenig, T. K., Lamarque, J.-F., Liu, C., Luo, J., Luo, Z. J., Montzka, D. D., Nicely, J. M., Pierce, R. B., Riemer, D. D., Robinson, T., Romashkin, P., Saiz-Lopez, A., Schauffler, S., Shieh, O., Stell, M. H., Ullmann, K., Vaughan, G., Volkamer, R., and Wolfe, G.: The Convective Transport of 
Active Species in the Tropics (CONTRAST) Experiment, B. Am. Meteorol. Soc., 98, 106-128, https://doi.org/10.1175/bams-d-1400272.1, 2017.

Patnaude, R. and Diao, M.: Aerosol indirect effects on cirrus clouds based on global aircraft observations, Geophys. Res. Lett., 47, e2019GL086550, https://doi.org/10.1029/2019GL086550, 2020.

Penner, J. E., Chen, Y., Wang, M., and Liu, X.: Possible influence of anthropogenic aerosols on cirrus clouds and anthropogenic forcing, Atmos. Chem. Phys., 9, 879-896, https://doi.org/10.5194/acp-9-879-2009, 2009.

Penner, J. E., Zhou, C., Garnier, A., and Mitchell, D. L.: Anthropogenic Aerosol Indirect Effects in Cirrus Clouds, J. Geophys. Res.-Atmos., 123, 11652-11677, https://doi.org/10.1029/2018JD029204, 2018.

Prenni, A. J., Petters, M. D., Faulhaber, A., Carriço, C. M., Ziemann, P. J., Kreidenweis, S. M., and DeMott, P. J.: Heterogeneous ice nucleation measurements of secondary organic aerosol generated from ozonolysis of alkenes, Geophys. Res. Lett., 36, 1-5, https://doi.org/10.1029/2008GL036957, 2009.

Righi, M., Hendricks, J., Lohmann, U., Beer, C. G., Hahn, V., Heinold, B., Heller, R., Krämer, M., Ponater, M., Rolf, C., Tegen, I., and Voigt, C.: Coupling aerosols to (cirrus) clouds in the global EMAC-MADE3 aerosol-climate model, Geosci. Model Dev., 13, 1635-1661, https://doi.org/10.5194/gmd-131635-2020, 2020.

Sassen, K., Wang, Z., and Liu, D.: Global distribution of cirrus clouds from CloudSat/cloud-aerosol lidar and infrared pathfinder satellite observations (CALIPSO) measurements, J. Geophys. Res.-Atmos., 113, 1-12, https://doi.org/10.1029/2008JD009972, 2008.

Schiller, C., Krämer, M., Afchine, A., Spelten, N., and Sitnikov, N.: Ice water content of Arctic, midlatitude, and tropical cirrus, J. Geophys. Res.-Atmos., 113, 1-12, https://doi.org/10.1029/2008JD010342, 2008.

Shi, X. and Liu, X.: Effect of cloud-scale vertical velocity on the contribution of homogeneous nucleation to cirrus formation and radiative forcing, Geophys. Res. Lett., 43, 6588-6595, https://doi.org/10.1002/2016GL069531, 2016.

Shi, X., Liu, X., and Zhang, K.: Effects of pre-existing ice crystals on cirrus clouds and comparison between different ice nucleation parameterizations with the Community Atmosphere Model (CAM5), Atmos. Chem. Phys., 15, 1503-1520, https://doi.org/10.5194/acp-15-1503-2015, 2015.

Stephens, B. B., Long, M. C., Keeling, R. F., Kort, E. A., Sweeney, C., Apel, E. C., Atlas, E. L., Beaton, S., Bent, J. D., Blake, N. J., Bresch, J. F., Casey, J., Daube, B. C., Diao, M., Diaz, E., Dierssen, H., Donets, V., Gao, B.-C., Gierach, M., Green, R., Haag, J., Hayman, M., Hills, A. J., Hoecker-Martínez, M. S., Honomichl, S. B., Hornbrook, R. S., Jensen, J. B., Li, R.-R., McCubbin, I., McKain, K., Morgan, E. J., Nolte, S., Powers, J. G., Rainwater, B., Randolph, K., Reeves, M., Schauffler, S. M., Smith, K., Smith, M., Stith, J., Stossmeister, G., Toohey, D. W., and Watt, A. S.: The $\mathrm{O}_{2} / \mathrm{N}_{2}$ Ratio and $\mathrm{CO}_{2}$ Airborne Southern Ocean Study, B. Am. Meteorol. Soc., 99, 381-402, https://doi.org/10.1175/BAMS-D-16-0206.1, 2018.

Stephens, G. and Webster, P.: Clouds and climate: Sensitivity of simple systems, J. Atmos. Sci., 38, 235-247, 1981.
Storelvmo, T. and Herger, N.: Cirrus cloud susceptibility to the injection of ice nuclei in the upper troposphere, J. Geophys. Res. 119, 2375-2389, https://doi.org/10.1002/2013JD020816, 2014.

Tan, X., Huang, Y., Diao, M., Bansemer, A., Zondlo, M. A., DiGangi, J. P., Volkamer, R., and Hu, Y.: An assessment of the radiative effects of ice supersaturation based on in situ observations, Geophys. Res. Lett., 43, 11039-11047, https://doi.org/10.1002/2016GL071144, 2016.

Thorsen, T. J., Fu, Q., Comstock, J. M., Sivaraman, C., Vaughan, M. A., Winker, D. M., and Turner, D. D.: Macrophysical properties of tropical cirrus clouds from the CALIPSO satellite and from ground-based micropulse and Raman lidars, J. Geophys. Res.Atmos., 118, 9209-9220, https://doi.org/10.1002/jgrd.50691, 2013.

Tseng, H.-H. and Fu, Q.: Temperature control of the variability of tropical tropopause layer cirrus clouds, J. Geophys. Res.-Atmos., 122, 11062-11075, https://doi.org/10.1002/2017JD027093, 2017.

UCAR/NCAR - Earth Observing Laboratory: Vertical Cavity Surface Emitting Laser Hygrometer (VCSEL), Version 1.0, UCAR/NCAR - Earth Observing Laboratory, https://doi.org/10.5065/D6Z31X06, 2009.

UCAR/NCAR - Earth Observing Laboratory: Low Rate (LRT - 1 sps) Navigation, State Parameter, and Microphysics Flight-Level Data (NetCDF), Version 3.0, UCAR/NCAR - Earth Observing Laboratory, https://doi.org/10.5065/D6BC3WKB, 2018a.

UCAR/NCAR - Earth Observing Laboratory: Low Rate (LRT - 1 sps) Navigation, State Parameter, and Microphysics Flight-Level Data, Version 1.2, UCAR/NCAR - Earth Observing Laboratory, https://doi.org/10.5065/D6TX3CK0, 2018b.

UCAR/NCAR - Earth Observing Laboratory: Low Rate (LRT - 1 sps) Navigation, State Parameter, and Microphysics Flight-Level Data, Version 1.1, UCAR/NCAR - Earth Observing Laboratory, https://doi.org/10.5065/D65T3HWR, 2018c.

UCAR/NCAR - Earth Observing Laboratory: Low Rate (LRT - 1 sps) Navigation, State Parameter, and Microphysics Flight-Level Data, Version 2.0, UCAR/NCAR - Earth Observing Laboratory, https://doi.org/10.5065/D6NZ85Z4, 2019a.

UCAR/NCAR - Earth Observing Laboratory: Low Rate (LRT - 1 sps) Navigation, State Parameter, and Microphysics Flight-Level Data, Version 5.0, UCAR/NCAR - Earth Observing Laboratory, https://doi.org/10.5065/D6JW8C64, 2019b.

UCAR/NCAR - Earth Observing Laboratory: Low Rate (LRT - 1 sps) Navigation, State Parameter, and Microphysics Flight-Level Data, Version 5.0, UCAR/NCAR - Earth Observing Laboratory, https://doi.org/10.5065/D6QF8R6R, 2019c.

UCAR/NCAR - Earth Observing Laboratory: Low Rate (LRT - 1 sps) Navigation, State Parameter, and Microphysics Flight-Level Data, Version 3.0, UCAR/NCAR - Earth Observing Laboratory, https://doi.org/10.5065/D6V40SK6, 2019d.

UCAR/NCAR - Earth Observing Laboratory: Low Rate (LRT - 1 sps) Navigation, State Parameter, and Microphysics Flight-Level Data, Version 3.0, UCAR/NCAR - Earth Observing Laboratory, https://doi.org/10.5065/D6CZ35HX, 2019e.

UCAR/NCAR - Earth Observing Laboratory: Low Rate (LRT - 1 sps) Navigation, State Parameter, and Microphysics Flight-Level Data, Version 2.0, UCAR/NCAR - Earth Observing Laboratory, https://doi.org/10.5065/D61R6NV5, $2019 f$. 
UCAR/NCAR - Earth Observing Laboratory: Low Rate (LRT - 1 sps) Navigation, State Parameter, and Microphysics Flight-Level Data, Version 3.0, UCAR/NCAR - Earth Observing Laboratory, https://doi.org/10.5065/D6668BHR, 2019g.

Volkamer, R., Baidar, S., Campos, T. L., Coburn, S., DiGangi, J. P., Dix, B., Eloranta, E. W., Koenig, T. K., Morley, B., Ortega, I., Pierce, B. R., Reeves, M., Sinreich, R., Wang, S., Zondlo, M. A., and Romashkin, P. A.: Aircraft measurements of BrO, IO, glyoxal, $\mathrm{NO}_{2}, \mathrm{H}_{2} \mathrm{O}, \mathrm{O}_{2}-\mathrm{O}_{2}$ and aerosol extinction profiles in the tropics: comparison with aircraft-/ship-based in situ and lidar measurements, Atmos. Meas. Tech., 8, 2121-2148, https://doi.org/10.5194/amt-8-2121-2015, 2015.

Wang, M. and Penner, J. E.: Cirrus clouds in a global climate model with a statistical cirrus cloud scheme, Atmos. Chem. Phys., 10, 5449-5474, https://doi.org/10.5194/acp-10-5449-2010, 2010.

Wang, M., Liu, X., Zhang, K., and Comstock, J. M.: Aerosol effects on cirrus through ice nucleation in the Community Atmosphere Model CAM5 with a statistical cirrus scheme, J. Adv. Model. Earth Syst., 6, 513-526, https://doi.org/10.1002/2014MS000339, 2014a.

Wang, Y., Liu, X., Hoose, C., and Wang, B.: Different contact angle distributions for heterogeneous ice nucleation in the Community Atmospheric Model version 5, Atmos. Chem. Phys., 14, 1041110430, https://doi.org/10.5194/acp-14-10411-2014, 2014b.

Wofsy, S. C.: HIAPER Pole-to-Pole Observations (HIPPO): Finegrained, global-scale measurements of climatically important atmospheric gases and aerosols, Philos. T. R. Soc. A, 369, 2073 2086, https://doi.org/10.1098/rsta.2010.0313, 2011.

Wolf, V., Kuhn, T., Milz, M., Voelger, P., Krämer, M., and Rolf, C.: Arctic ice clouds over northern Sweden: microphysical properties studied with the Balloon-borne Ice Cloud particle Imager B-ICI, Atmos. Chem. Phys., 18, 17371-17386, https://doi.org/10.5194/acp-18-17371-2018, 2018.

Wu, C., Liu, X., Diao, M., Zhang, K., Gettelman, A., Lu, Z., Penner, J. E., and Lin, Z.: Direct comparisons of ice cloud macroand microphysical properties simulated by the Community Atmosphere Model version 5 with HIPPO aircraft observations, Atmos. Chem. Phys., 17, 4731-4749, https://doi.org/10.5194/acp17-4731-2017, 2017.
Zhang, G. J. and McFarlane, N. A.: Sensitivity of climate simulations to the parameterization of cumulus convection in the canadian climate centre general circulation model, Atmos.-Ocean, 33, 407-446, https://doi.org/10.1080/07055900.1995.9649539, 1995.

Zhang, K., Liu, X., Wang, M., Comstock, J. M., Mitchell, D. L., Mishra, S., and Mace, G. G.: Evaluating and constraining ice cloud parameterizations in CAM5 using aircraft measurements from the SPARTICUS campaign, Atmos. Chem. Phys., 13, 4963-4982, https://doi.org/10.5194/acp-13-4963-2013, 2013.

Zhang, Y., MacKe, A., and Albers, F.: Effect of crystal size spectrum and crystal shape on stratiform cirrus radiative forcing, Atmos. Res., 52, 59-75, https://doi.org/10.1016/S01698095(99)00026-5, 1999.

Zhao, B., Liou, K.-N., Gu, Y., Jiang, J. H., Li, Q., Fu, R., Huang, L., Liu, X., Shi, X., Su, H., and He, C.: Impact of aerosols on ice crystal size, Atmos. Chem. Phys., 18, 1065-1078, https://doi.org/10.5194/acp-18-1065-2018, 2018.

Zhao, B., Wang, Y., Gu, Y., Liou, K. N., Jiang, J. H., Fan, J., Liu, X., Huang, L., and Yung, Y. L.: Ice nucleation by aerosols from anthropogenic pollution, Nat. Geosci., 12, 602607, https://doi.org/10.1038/s41561-019-0389-4, 2019.

Zhou, C., Penner, J. E., Lin, G., Liu, X., and Wang, M.: What controls the low ice number concentration in the upper troposphere?, Atmos. Chem. Phys., 16, 12411-12424, https://doi.org/10.5194/acp-16-12411-2016, 2016.

Zondlo, M. A., Paige, M. E., Massick, S. M., and Silver, J. A.: Vertical cavity laser hygrometer for the National Science Foundation Gulfstream-V aircraft, J. Geophys. Res.-Atmos., 115, 1-14, https://doi.org/10.1029/2010JD014445, 2010. 